\title{
Article \\ Pathogenic Variability of the Jackfruit-Bronzing Bacterium Pantoea stewartii Subspecies stewartii Infection to Jackfruit Varieties and Its Pivotal Plant Hosts in Malaysia
}

\author{
Nuraizat Abidin ${ }^{1}$, Siti Izera Ismail ${ }^{1}{ }^{(}$, Ganesan Vadamalai ${ }^{1}$, Mohd Termizi Yusof ${ }^{2}\left({ }^{\circ}\right.$, Mansor Hakiman ${ }^{3,4}{ }^{\circledR}$, \\ Daljit Singh Karam ${ }^{5}$ and Dzarifah Zulperi ${ }^{1,4, *(1)}$ \\ 1 Department of Plant Protection, Faculty of Agriculture, Universiti Putra Malaysia, \\ Serdang 43400, Selangor, Malaysia; nzatabidin@gmail.com (N.A.); izera@upm.edu.my (S.I.I.); \\ ganesanv@upm.edu.my (G.V.) \\ 2 Department of Microbiology, Faculty of Biotechnology and Biomolecular Sciences, Universiti Putra Malaysia, \\ Serdang 43400, Selangor, Malaysia; mohdtermizi@upm.edu.my \\ 3 Department of Crop Science, Faculty of Agriculture, Universiti Putra Malaysia, \\ Serdang 43400, Selangor, Malaysia; mhakiman@upm.edu.my \\ 4 Laboratory of Sustainable Resources Management, Institute of Tropical Forestry and Forest Products, \\ Universiti Putra Malaysia, Serdang 43400, Selangor, Malaysia \\ 5 Department of Land Management, Faculty of Agriculture, Universiti Putra Malaysia, \\ Serdang 43400, Selangor, Malaysia; daljitsingh@upm.edu.my \\ * Correspondence: dzarifah@upm.edu.my; Tel.: +60-3-9769-4812
}

Citation: Abidin, N.; Ismail, S.I.; Vadamalai, G.; Yusof, M.T.; Hakiman, M.; Karam, D.S.; Zulperi, D. Pathogenic Variability of the Jackfruit-Bronzing Bacterium Pantoea sterwartii Subspecies stewartii Infection to Jackfruit Varieties and Its Pivotal Plant Hosts in Malaysia. Agronomy 2021, 11, 2113. https://doi.org/ 10.3390/agronomy11112113

Academic Editors: Salvatore Davino and Slavica Matic

Received: 29 September 2021

Accepted: 13 October 2021

Published: 21 October 2021

Publisher's Note: MDPI stays neutral with regard to jurisdictional claims in published maps and institutional affiliations.

Copyright: () 2021 by the authors. Licensee MDPI, Basel, Switzerland. This article is an open access article distributed under the terms and conditions of the Creative Commons Attribution (CC BY) license (https:// creativecommons.org/licenses/by/ $4.0 /)$.
Abstract: Infection with Pantoea stewartii subspecies stewartii, which causes jackfruit-bronzing disease, is a huge problem faced by the jackfruit industry in Malaysia. This study was carried out to assess the disease ratings and aggressiveness performance of 28 Pantoea stewartii subspecies stewartii isolated from jackfruit-bronzing diseased jackfruits from four collection areas (Jenderam in Selangor State, Maran and Muadzam Shah in Pahang State, and Ipoh in Perak State) in Peninsular Malaysia, inoculated into jackfruit varieties (Tekam Yellow J33, Hong J34 and Subang Chap Boy J39), the sweetcorn variety, Mas Madu (two-week-old seedlings and nine-week-old seedlings), the cucumber variety, Rocky, and the pineapple variety, MD2. The results revealed that Pantoea stewartii subspecies stewartii produced symptoms upon all inoculations in the pathogenicity testing, thus fulfilling Koch's postulates, except in the case of J39 and sweetcorn (two-week-old seedlings). No disease symptoms (disease rating 0) were observed in J39 and sweetcorn (two-week-old seedlings) within 14 days post-inoculation (14 dpi). The disease progression (based on disease ratings) proved that the jackfruit variety J39 was the most resistant, whereas J33 and J34 were susceptible to jackfruit-bronzing disease. The disease ratings of the 14-dpi period revealed a variability of disease progression among the 28 bacterial isolates, where the isolate JEN-14 had the fastest and highest disease ratings when inoculated into J33, J34, nine-week-old sweetcorn seedlings, cucumber, and pineapple. Likewise, the AUDPC value, based on disease rating, across the 28 isolates indicated that JEN-14 is the most aggressive and significant of the isolates (J33, J34, nine-week-old sweetcorn seedlings, cucumber, and cucumber pineapple inoculation; $p<0.05$ ). Even though isolates from Jenderam (other than JEN-14) and Maran had better disease ratings and the area under the disease progress curve (AUDPC) values than isolates from Muadzam Shah and Ipoh, no significant differences were found among the isolates $(p<0.05)$. Based on our findings, we identified the isolate JEN-14 as the best potential candidate to assist in jackfruit-bronzing disease resistance breeding in the future. Last but not least, the methods, disease ratings, and variations of the aggressiveness profiles among the isolates from this study may be beneficial and significant by providing disease-rating references and appropriate screening approaches when selecting the most appropriately aggressive isolates for evaluating the defense response in the disease resistance breeding program.

Keywords: jackfruit-bronzing; Pantoea stewartii subspecies stewartii; pathogenicity; disease rating; AUDPC; aggressiveness 


\section{Introduction}

Jackfruit (Artocarpus heterophyllus) is a crop grown and cultivated economically in over 60 countries worldwide, especially in Asia, with India and Bangladesh being the major international producers of jackfruits [1]. In Malaysia, jackfruit is included as one of the country's top ten essential crops, with a total production of 31,281.30 mt and jackfruitplantations covered around 4656.92 ha in 2019 [2]. Jackfruit is also included as one of Malaysia's top export fruits; a total of $392,598 \mathrm{~kg}$ of whole fruits and 78,076 kg of minimally processed jackfruit were exported to Australia, Canada, China, Indonesia, Japan, New Zealand, the USA, and Vietnam in 2020 [3]. Among the 15 current jackfruit varieties cultivated in Malaysia, the Department of Agriculture (DOA) in Malaysia recommended cultivating Tekam Yellow (J33) [4,5]. It is one of the most popular varieties and is the consumers' preference, due to its sweet taste $[4,6]$.

Jackfruit-bronzing disease on the variety J33 was first reported in Muadzam Shah, Pahang, Peninsular Malaysia in 2017 [7] and remains a current threat in the jackfruit industries in Malaysia [3,8,9]. Jackfruit plantations with evidence of jackfruit-bronzing disease have also been reported in the Philippines and Mexico [10,11]. Based on the external appearance of the fruit, the bronzing disease looks symptomless, but the pulps and rags show a yellowish orange to reddish discoloration and rusty or bronzed specks [7-11]. Thus, the symptoms exhibited by diseased crops affect the crop plants' appearance, quality, and yield, to the extent that the fruit cannot be sold in the market [12,13]. Therefore, jackfruitbronzing disease is included as a major quarantine pest and disease affecting export [3]. The infected or damaged fruit will be discarded before or after arrival in the destination country [3,14].

This disease is caused by an aerobic, Gram-negative bacterium, Pantoea stewartii subspecies stewartii (P. stewartii subsp. stewartii) [10]. P. stewartii subsp. stewartii is the causal agent of Stewart's wilt in Zea mays [15-19]. Moreover, P. stewartii subsp. stewartii was reported as the causal agent of bacterial leaf wilt disease in sugarcane and of leaf blight in rice [20-22]. Studies of $P$. stewartii subsp. stewartii transmission primarily focused on Zea mays $[17,21,23,24]$. The main vector for the transmission of Stewart's wilt is the corn flea beetle (Chaetocnema pulicaria Melsheimer), within which P. stewartii subsp. stewartii overwinters in the gut, and when the vector becomes an adult, it emerges from its dormancy and transmits the disease via the feeding wound of plants [23]. The xylem area of the Zea mays vascular system is then colonized and the bacteria multiply in high cell densities, promoting EPS-encased biofilm production, motility, dispersion, and adhesion for Stewart's disease development [25]. Only recently, a study by [26] revealed that the ChrysSA genus flea beetle was associated with jackfruit-bronzing disease in Mexico. It was found that the bacterium isolate AG024-VI, isolated from the ChrysSA genus flea beetle, was confirmed as P. stewartii subsp. stewartii and was pathogenic to jackfruit [26]. The processes of how this vector invades jackfruit are yet to be studied.

Performing pathogenicity tests is vital and is needed for confirmation; otherwise, the status of the microbe as a novel pathogen cannot be proven [27]. Other than performing whole-plant and attached field inoculation assays, detached leaves, branches, and fruits inoculation techniques have been adopted and preferred in recent studies [28-31] due to the convenience of performing the inoculation testing of a large number of isolates simultaneously, allowing tighter control of the environmental conditions for replication tests. Koch's hypothesis has been proven as a standard test for evidence of a microbe as a pathogen, showing the relationship between the parasite and the hosts, and as an approach for determining disease causation [32]. The infection process in other species also needs to be studied, as plant species are susceptible and succumb to various plant pathogens $[33,34]$.

Moreover, studies on aggressiveness are still lacking, even though aggressiveness is an essential quantitative component in pathogenicity [35]. Nevertheless, the different levels of aggressiveness observed in pathogenicity studies aid researchers and plant breeders in selecting and screening for plant resistance and defense responses $[35,36]$. This advancement provides future options for breeders to develop disease management strategies via reliable 
disease assessment, such as performing artificial inoculation using the most aggressive isolate, to evaluate the resistance of the various breed crop varieties [35-38]. In addition, the action of aggressiveness on different varieties or hosts heightens the disease progression and rating results as it often reflects the degree of host tolerance and susceptibility [39]. The assessment of disease performance, therefore, reflects the degree of host susceptibility and pathogen aggressiveness [39].

The results of previous pathogenicity testing of the jackfruit-bronzing disease reported the symptoms of $P$. stewartii subsp. stewartii-infected jackfruit, including reddish discoloration or bronzing, or rusty specks with yellowish discoloration of the jackfruit [7-11]. Moreover, the inoculation of sweetcorn and pineapple with P. stewartii subsp. stewartii elicited symptoms, causing the appearance of linear, pale yellow streaks with wavy margins. In addition, the fruit may turn brown and desiccate (Stewart's wilt symptom) in sweetcorn and trigger localized lesion symptoms in pineapple [10]. However, a study on the aggressiveness of the jackfruit-bronzing isolates via pathogenicity testing is still lacking. In addition, no pathogenicity test on different jackfruit varieties (other than the infected variety) has been conducted regarding the jackfruit-bronzing pathogen. Any study of the performance of the jackfruit-bronzing bacterium on resistance and susceptible jackfruit varieties is yet to be conducted. The only closely related study of pathogenicity tests for $P$. stewartii subsp. stewartii were the aggressiveness performance of $P$. stewartii subsp. stewartii isolates that were isolated from infected Zea mays (Stewart's wilt) in Indonesia on hybrid, open-pollinated and sweetcorn maize varieties by [40]. Their findings ascertained that sweetcorn varieties were the most susceptible, compared to the other two.

Therefore, the current study emphasizes the aggressiveness of the jackfruit-bronzing pathogen, based on pathogenicity tests, with the aims of (i) developing a disease rating reference guide (with pictures) and (ii) determining and assessing the aggressiveness of P. stewartii subsp. stewartii isolates when inoculated into jackfruit varieties, cucumber, and pineapple, using isolates collected from four sites in Peninsular Malaysia. Furthermore, the outcome from this study would assist in the breeding of jackfruit-bronzing-resistant varieties that may offer a similar taste and quality to J33.

\section{Materials and Methods}

\subsection{Bacterial Isolates}

Twenty-eight bronzing-related disease isolates (Table 1) from outbreaks in jackfruit plantation areas in Peninsular Malaysia (Jenderam from Selangor State, Maran and Muadzam Shah from Pahang State, and Ipoh from Perak State) were selected from a previous study [8]. All 28 isolates were verified as P. stewartii subsp. stewartii and as pathogenic (with a positive hypersensitivity reaction (HR)) [8]. The isolates were grown from a frozen glycerol stock onto nutrient broth yeast (NBY) and King's B media for $24-48 \mathrm{~h}$ at $28{ }^{\circ} \mathrm{C}$ for pathogenicity and inoculation purposes.

\subsection{Pathogenicity Test}

Different varieties of detached jackfruit J33, Hong (J34), and Subang Chap Boy (J39) were used in this experiment. These healthy jackfruit varieties were provided by the DOA, Malaysia. A pathogenicity test was performed with jackfruit flesh removed from disinfected healthy jackfruit, rinsed with a small amount of $10 \%$ ethanol, and washed twice with distilled water to ensure that there was no contamination. The jackfruit pulps were dried on sterile tissue paper and placed in a sterile petri dish with a layer of sterile filter paper. The pathogenicity test was conducted by injecting $10 \mathrm{~mL}$ of a $10^{8} \mathrm{CFU} / \mathrm{mL}$ (as determined by McFarland Standard, bioMérieux, Marcy-l'Etoile, France) suspension of the pure P. stewartii subsp. stewartii into jackfruit flesh (4 replicates per isolate) [10]. The P. stewartii subsp. stewartii suspension was injected with a syringe to a depth of $10 \mathrm{~mm}$, with 3 inoculation sites on each pulp. Control jackfruits were treated with sterile distilled water. 
The jackfruits inoculated with all 28 bacterial isolates or with the control (distilled water) were appropriately sealed using parafilm and incubated at $28^{\circ} \mathrm{C}$ in a controlled chamber for the treatments. Observations and examinations for the development of symptoms were recorded daily for up to 2 weeks after inoculation. The assessment of bronzing symptoms was examined after 2 weeks of incubation. The experiment was repeated 3 times.

Table 1. Pantoea stewartii subspecies stewartii isolates used in this study $(n=28)$ [8].

\begin{tabular}{|c|c|c|c|c|c|c|c|c|c|}
\hline $\mathrm{NS}^{1}$ & $\begin{array}{l}\text { Isolate } \\
\text { Name }\end{array}$ & Host & $\begin{array}{l}\text { Jackfruit } \\
\text { Variety }\end{array}$ & $\begin{array}{c}\text { Collection } \\
\text { Area }\end{array}$ & State & $\begin{array}{c}\text { Year } \\
\text { Collected }\end{array}$ & Symptom & $\begin{array}{r}\text { GenBank } \\
\text { Accession }\end{array}$ & $\mathrm{HR}^{2}$ \\
\hline 1 & JEN-3 & $\mathrm{AH}^{3}$ & $\mathrm{~J} 33^{4}$ & Jenderam & Selangor & 2017 & $\mathrm{RD}^{5}$ & MK802515 & +7 \\
\hline 2 & JEN-5 & $\mathrm{AH}$ & $\mathrm{J} 33$ & Jenderam & Selangor & 2017 & RD & MK802516 & + \\
\hline 3 & JEN-8 & $\mathrm{AH}$ & J33 & Jenderam & Selangor & 2017 & RD & MK802517 & + \\
\hline 4 & JEN-13 & $\mathrm{AH}$ & J33 & Jenderam & Selangor & 2017 & BSYD $^{6}$ & MK802518 & + \\
\hline 5 & JEN-14 & $\mathrm{AH}$ & J33 & Jenderam & Selangor & 2017 & BSYD & MK802519 & + \\
\hline 6 & JEN-16 & $\mathrm{AH}$ & J33 & Jenderam & Selangor & 2017 & BSYD & MK802520 & + \\
\hline 7 & JEN-20 & $\mathrm{AH}$ & J33 & Jenderam & Selangor & 2017 & RD & MK802521 & + \\
\hline 8 & MAR-A & $\mathrm{AH}$ & $\mathrm{J} 33$ & Maran & Pahang & 2017 & BSYD & MK802522 & + \\
\hline 9 & MAR-D & $\mathrm{AH}$ & J33 & Maran & Pahang & 2017 & RD & MK802523 & + \\
\hline 10 & MAR-E & $\mathrm{AH}$ & $\mathrm{J} 33$ & Maran & Pahang & 2017 & BSYD & MK802524 & + \\
\hline 11 & MAR-F & $\mathrm{AH}$ & J33 & Maran & Pahang & 2017 & BSYD & MK802525 & + \\
\hline 12 & MAR-H & $\mathrm{AH}$ & J33 & Maran & Pahang & 2017 & RD & MK802526 & + \\
\hline 13 & MAR-M & $\mathrm{AH}$ & J33 & Maran & Pahang & 2017 & BSYD & MK802527 & + \\
\hline 14 & MAR-Q & $\mathrm{AH}$ & $\mathrm{J} 33$ & Maran & Pahang & 2017 & BSYD & MK802528 & + \\
\hline 15 & MS-3 & $\mathrm{AH}$ & $\mathrm{J} 33$ & Muadzam Shah & Pahang & 2017 & RD & MK802529 & + \\
\hline 16 & MS-4 & $\mathrm{AH}$ & $\mathrm{J} 33$ & Muadzam Shah & Pahang & 2017 & BSYD & MK802530 & + \\
\hline 17 & MS-8 & $\mathrm{AH}$ & $\mathrm{J} 33$ & Muadzam Shah & Pahang & 2017 & BSYD & MK802531 & + \\
\hline 18 & MS-B & $\mathrm{AH}$ & $\mathrm{J} 33$ & Muadzam Shah & Pahang & 2017 & $\mathrm{RD}$ & MK802532 & + \\
\hline 19 & MS-C & $\mathrm{AH}$ & $\mathrm{J} 33$ & Muadzam Shah & Pahang & 2017 & BSYD & MK802533 & + \\
\hline 20 & MS-F & $\mathrm{AH}$ & $\mathrm{J} 33$ & Muadzam Shah & Pahang & 2017 & BSYD & MK802534 & + \\
\hline 21 & MS-H & $\mathrm{AH}$ & $\mathrm{J} 33$ & Muadzam Shah & Pahang & 2017 & BSYD & MK802535 & + \\
\hline 22 & IPOH-5 & $\mathrm{AH}$ & $\mathrm{J} 33$ & Ipoh & Perak & 2017 & BSYD & MK531591 & + \\
\hline 23 & IPOH-B & $\mathrm{AH}$ & $\mathrm{J} 33$ & Ipoh & Perak & 2017 & RD & MK802536 & + \\
\hline 24 & IPOH-I & $\mathrm{AH}$ & $\mathrm{J} 33$ & Ipoh & Perak & 2017 & BSYD & MK802537 & + \\
\hline 25 & IPOH-M & $\mathrm{AH}$ & J33 & Ipoh & Perak & 2017 & BSYD & MK802538 & + \\
\hline 26 & IPOH-S & $\mathrm{AH}$ & $\mathrm{J} 33$ & Ipoh & Perak & 2017 & BSYD & MK802539 & + \\
\hline 27 & IPOH-V & $\mathrm{AH}$ & $\mathrm{J} 33$ & Ipoh & Perak & 2017 & RD & MK802540 & + \\
\hline 28 & IPOH-Z & $\mathrm{AH}$ & $\mathrm{J} 33$ & Ipoh & Perak & 2017 & RD & MK802541 & + \\
\hline
\end{tabular}

Abbreviations: $\mathrm{NS}^{1}=$ no. of isolates; $\mathrm{HR}^{2}=$ hypersensitivity reaction; $\mathrm{AH}^{3}=$ Artocarpus heterophyllus; $\mathrm{J}^{3}{ }^{4}=$ Tekam Yellow J33; $\mathrm{RD}^{5}=$ reddish discoloration; BSYD ${ }^{6}=$ rusty or bronzing specks with yellowish discoloration; $+{ }^{7}=$ positive reaction.

\subsection{Other Hosts Tests on Sweetcorn, Cucumber and Pineapple}

Inoculation of P. stewartii subsp. stewartii was performed on the sweetcorn (Zea mays) variety, Mas Madu, the cucumber (Cucumis sativus) variety, Rocky, and the pineapple (Ananas comosus) variety, MD2. These healthy sweetcorn, cucumber, and pineapple fruits were provided by the DOA, Malaysia. A glasshouse experiment with P. stewartii subsp. stewartii on sweetcorn was performed on two- and nine-week-old healthy sweetcorn $[10,23,41]$. One milliliter of a $10^{8} \mathrm{CFU} / \mathrm{mL}$ (as determined by McFarland Standard, BioMérieux, Marcy-l'Etoile, France) bacterial suspension was injected into the stem of the sweetcorn. The inoculation sites were covered with sterile tissue, parafilm, and duct tape. Three inoculation sites were used on each sweetcorn stem. All 28 bacterial isolate treatments, together with the control (distilled water), were performed with 4 replicates of sweetcorn. The treatments were randomized using a completely randomized layout with the statistical tool for agricultural research (STAR) software (http:/ / bbi.irri.org/products, accessed on 10 May 2018). The glasshouse experiment was observed daily and was assessed 2 weeks after inoculation. The experiment was repeated 3 times. 
Fresh, healthy cucumbers and pineapple were cut into similar sizes (so as to fit inside the petri dish), rinsed with a small amount of $10 \%$ ethanol, and washed twice with distilled water to ensure that there was no contamination [10]. The cut fruit was dried on sterile tissue paper and placed on a sterile petri dish on a layer of sterile filter paper. Then, $1 \mathrm{~mL}$ of a $10^{8} \mathrm{CFU} / \mathrm{mL}$ (as determined by McFarland Standard, BioMérieux, Marcyl'Etoile, France) suspension was injected into healthy cut pineapple and cucumber (4 replicates per isolate). Next, the bacterial suspension was injected with a syringe to a depth of $10 \mathrm{~mm}$ into the pineapple and $5 \mathrm{~mm}$ into the cucumber, with 3 inoculation sites on each cut fruit.

For the treatments, the pineapple and cucumber, inoculated with all 28 bacterial isolates and the control (distilled water), were appropriately sealed using parafilm and incubated at $28{ }^{\circ} \mathrm{C}$ in a controlled chamber. The experiment was repeated 3 times. The observations and examinations for the development of symptoms on the pineapple and cucumber were recorded daily for up to 2 weeks of incubation. The samples were assessed after 2 weeks of incubation. The experiment was repeated 3 times.

\subsection{Disease Rating Assessment}

Assessment for the pathogenicity test and other hosts' inoculation (except for Stewart's wilt symptom) was developed based on the symptoms obtained in the study. The disease rating score was rated (0-4) using (i) the RAL ${ }^{\circledR}$ color chart [42], based on the color changes, and (ii) analysis using ImageJ software [43] and the Fiji distribution of ImageJ [43], based on the degree of severity of symptoms produced (Figures S1 and S2). The observation of Stewart's wilt was based on a previous study on the loss of turgidity of the leaves or possibly of the entire plants [33]. Stewart's wilt symptoms on sweetcorn were scored according to an ordinal rating scale of $0-9$, as illustrated by [44].

\subsection{Assessment of AUDPC and Statistical Analysis}

Data were presented as a median. Furthermore, the area under the disease progress curve (AUDPC) value of disease rating was calculated daily, from the initial day of the inoculation until the final day, using the following formula [45]:

$$
A U D P C=\sum_{i=1}^{n-1}\left(\frac{y_{i}+y_{i+1}}{2}\right)\left(t_{i+1}-t_{i}\right)
$$

where $n$ is the number of evaluations, $y_{i}$ is the values of the disease rating at the $i$ th observation, and $t_{i}$ is the assessment period at the $i$ th observation. Statistical analyses were conducted using $\mathrm{R}$ version v. 4.1.0. [46] and Rstudio v. 1.4.1717-3 [47], along with the $\mathrm{R}$ packages purrr, readxl, tidyverse, ggplot2, RColorBrewer, FSA, rcompanion, and patchwork [48-54]. The differences between data were subjected to the non-parametric Kruskal-Wallis test, followed by Dunn's post hoc test for the comparison of rank sums. The results were considered significant at $p<0.05$.

\subsection{Koch's Postulates on Jackfruit Varieties, Sweetcorn, Cucumber and Pineapple}

After 14 days of inoculation, all symptomatic and asymptomatic inoculated jackfruit varieties, two- and nine-week-old sweetcorn, cucumber, and pineapple, were re-isolated to confirm the presence of the bacterium. The inoculated samples were put inside clear polyethylene bags (plastic surface sprayed with alcohol $(70 \%)$ ), brought under laminar flow for surface sterilization. Symptomatic and asymptomatic samples were excised, cut, and rinsed with sterilized distilled water (containing $1 \%$ of sodium hypochlorite, Chlorox ${ }^{\mathrm{TM}}$ ) for $3 \mathrm{~min}$. The samples were then crushed and serially diluted 10-fold in sterile phosphate buffer (PB) [23]. Then, $100 \mu \mathrm{L}$ of each dilution was spread over nutrient broth yeast (NBY) medium and King's B medium, appropriately sealed and incubated in an inverted position at $28{ }^{\circ} \mathrm{C}$ for 24 to $48 \mathrm{~h}$. After incubation, isolated colonies were subcultured until pure colonies of suspected $P$. stewartii subsp. stewartii isolates were obtained. The expected colonies' morphology was lemon to orange-yellow or pale yellow, flat to convex, transparent with entire edges, and with medium growing. Biochemical tests consisted 
of Gram-staining, oxidase reaction, starch hydrolysis, gelatin liquefaction, motility test, and indole production were performed $[10,16,18,23]$ as well as using a specific primer pair, ES16/ESIG2c [22], for the fulfillment of Koch's postulates.

\section{Results}

\subsection{Disease Rating Assessment on Jackfruit}

An ordinal rating scale was developed, utilizing a reddish discoloration symptom scoring on jackfruits (Table 2 and Figure 1). Disease rating analysis for rusty or bronzing specks with yellowish discoloration symptoms was performed using ImageJ and the Fiji distribution of ImageJ. Rusty or bronzing specks with yellowish discoloration were developed and scored on an ordinal rating scale of symptoms, as illustrated (Table 3 and Figure 2). No disease symptoms appeared in the control jackfruit.
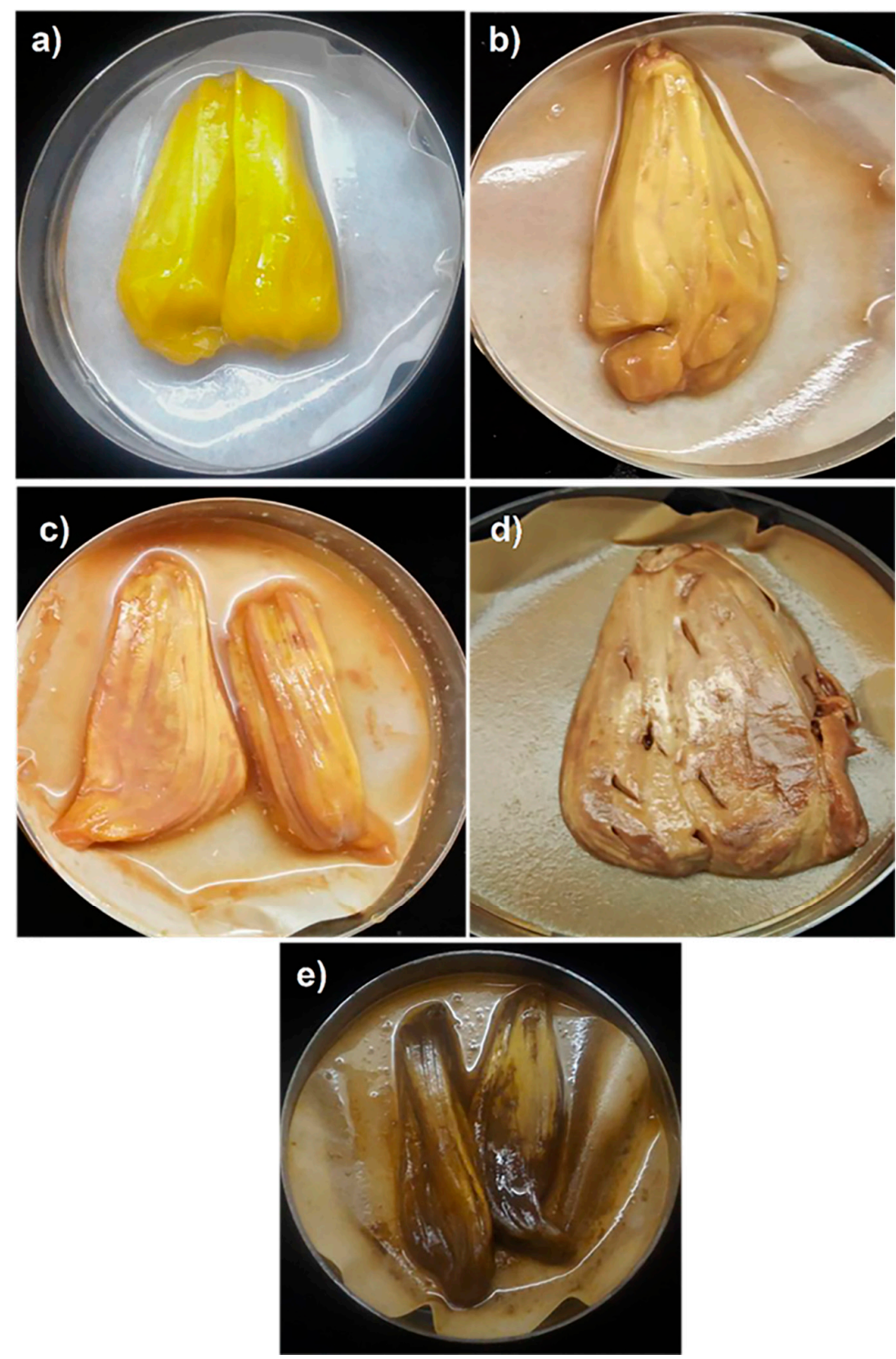

Figure 1. The disease rating of the reddish discoloration of jackfruit pulps (rating 0-4). (a) Disease rating 0 ; (b) disease rating 1 ; (c) disease rating 2; (d) disease rating 3; (e) disease rating 4. 

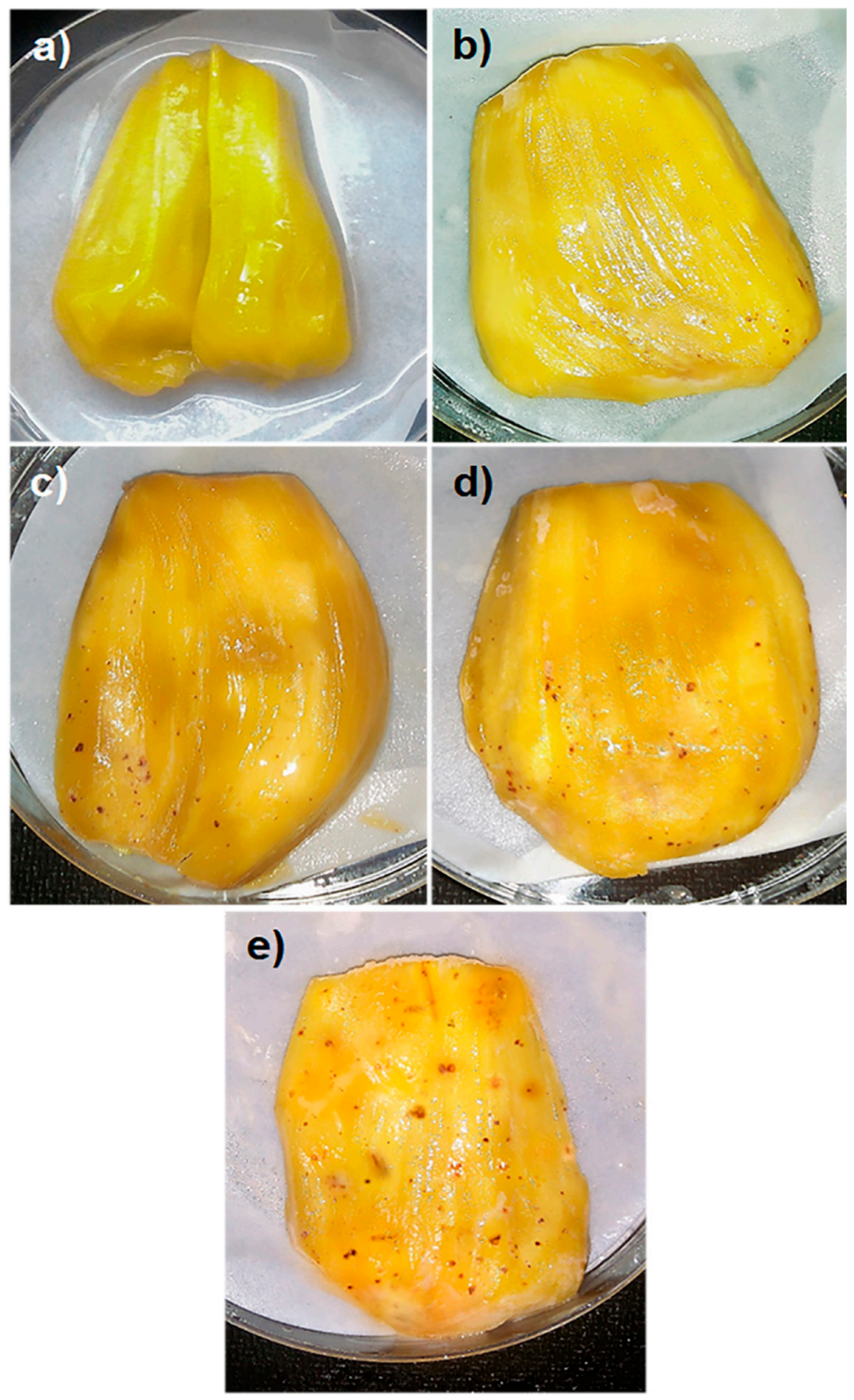

Figure 2. The disease rating of reddish discoloration of jackfruit pulps (rating 0-4). (a) Disease rating 0 ; (b) disease rating 1; (c) disease rating 2; (d) disease rating 3; (e) disease rating 4.

Table 2. The disease rating of reddish discoloration of jackfruit pulps (developed from this study).

\begin{tabular}{cc}
\hline Disease Rating & Description \\
\hline 0 & No symptom \\
1 & 3012 Beige Red \\
2 & 3022 Dark Salmon Red \\
3 & 3009 Oxide Red \\
4 & 3007 Black Red \\
\hline
\end{tabular}

Table 3. The disease rating of rusty or bronzing specks with yellowish discoloration of jackfruit pulps (developed from this study).

\begin{tabular}{cc}
\hline Disease Rating & Description \\
\hline 0 & No symptom \\
1 & Rusty or bronzing specks with yellowish discoloration covered $1-24 \%$ of the jackfruit \\
2 & Rusty or bronzing specks with yellowish discoloration covered $25-49 \%$ of the jackfruit \\
3 & Rusty or bronzing specks with yellowish discoloration covered $50-74 \%$ of the jackfruit \\
4 & Rusty or bronzing specks with yellowish discoloration covered $>75 \%$ of the jackfruit \\
\hline
\end{tabular}




\subsection{Disease Rating Assessment on Sweetcorn}

Inoculation of sweetcorn led to symptoms of pale or yellowish-green leaf streaks on the nine-week-old seedlings, and no symptoms were observed on the two-week-old seedlings (Figure 3). No disease symptoms appeared in the control seedling.
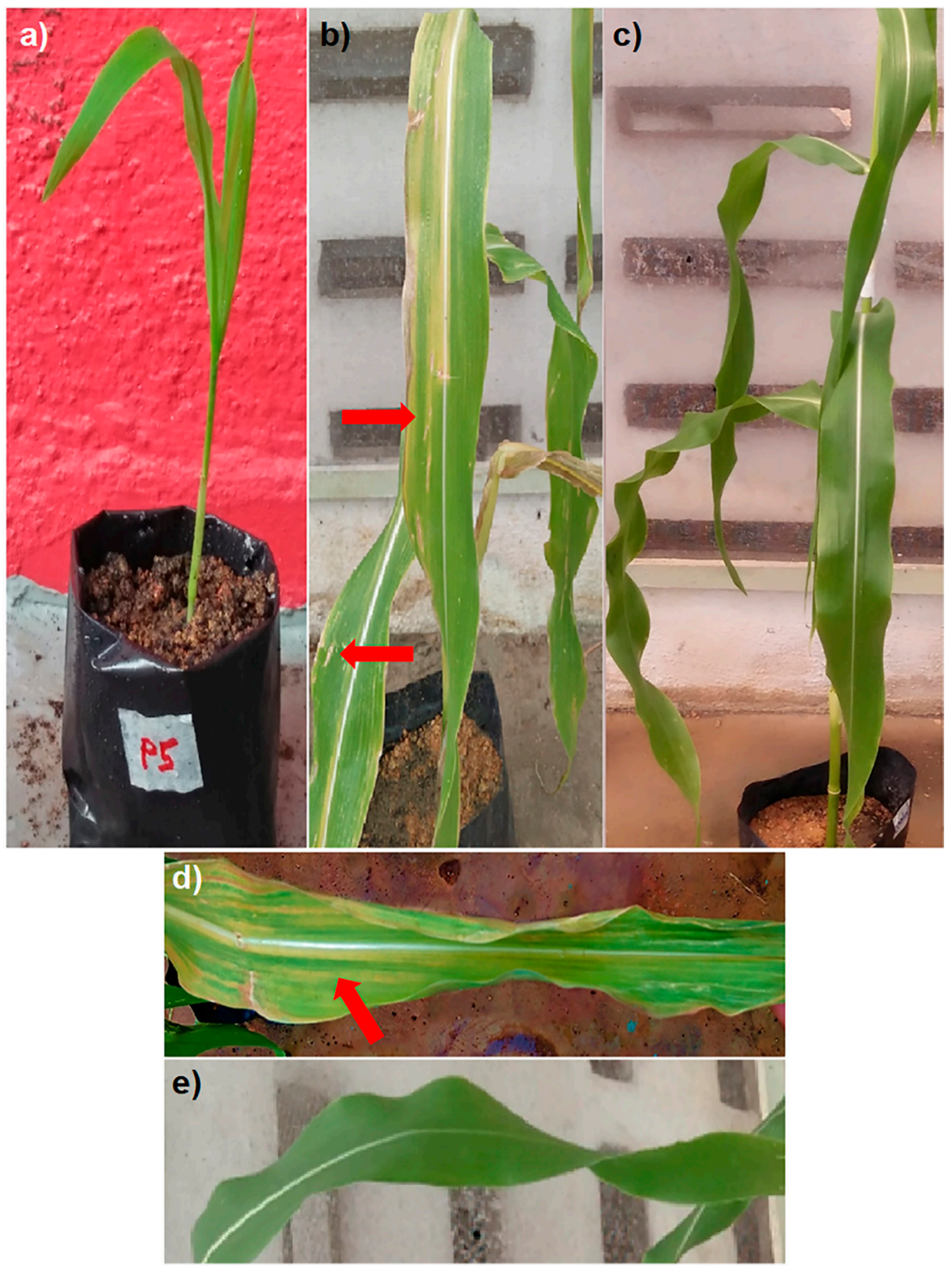

Figure 3. Inoculation of the Pantoea stewartii subspecies stewartii into sweetcorn, 14 days post-inoculation. (a) No symptoms on two-week-old seedlings inoculated with the isolate IPOH-5; (b) appearance of linear pale yellow streaks on nine-week-old seedlings inoculated with the isolate MAR-D; (c) control nine-week-old sweetcorn; (d) appearance of linear pale yellow streaks with wavy margins on isolate MS-C; (e) control sweetcorn. 


\subsection{Disease Rating Assessment on Cucumber}

Reddish discoloration symptom scoring for cucumber was developed on an ordinal rating scale (Table 4 and Figure 4). No disease symptoms appeared in the control cucumber.

Table 4. The disease rating of reddish discoloration of cucumber fruitlets (developed from this study).

\begin{tabular}{cc}
\hline Disease Rating & Description \\
\hline 0 & No symptom \\
1 & 2012 Salmon Orange \\
2 & 3012 Beige Red \\
3 & 3022 Dark Salmon Red \\
4 & 3011 Tomato Red \\
\hline
\end{tabular}
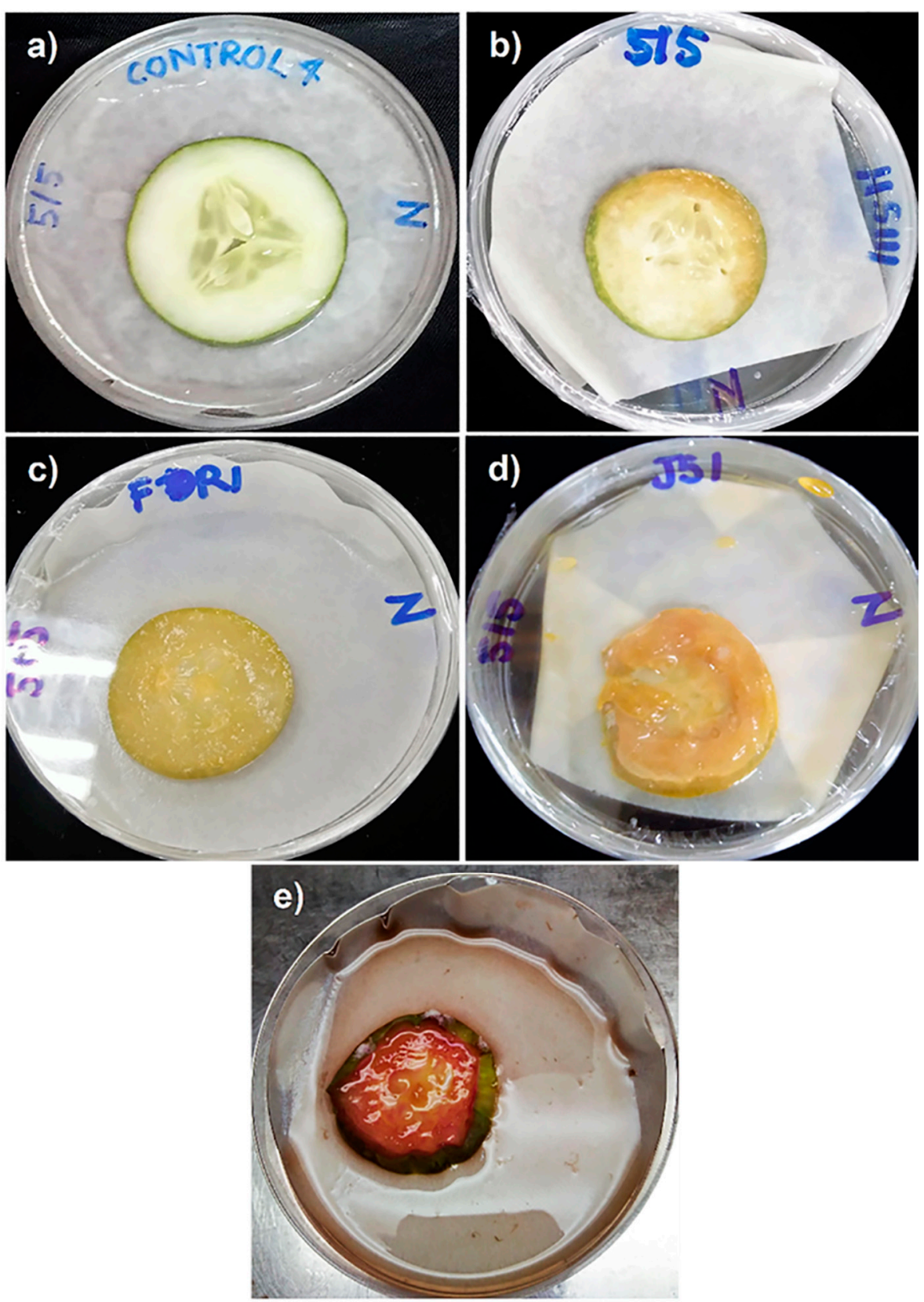

Figure 4. The disease rating of reddish discoloration of the cucumber fruitlet (rating 0-4). (a) Disease rating 0 ; (b) disease rating 1 ; (c) disease rating 2; (d) disease rating 3; (e) disease rating 4. 


\subsection{Disease Rating Assessment on Pineapple}

A disease rating analysis of the images taken was calculated, using ImageJ and the Fiji distribution of ImageJ. Localized lesion-symptom scoring on the pineapple was developed on an ordinal rating scale (Table 5 and Figure 5). No disease symptoms appeared in the control pineapple.
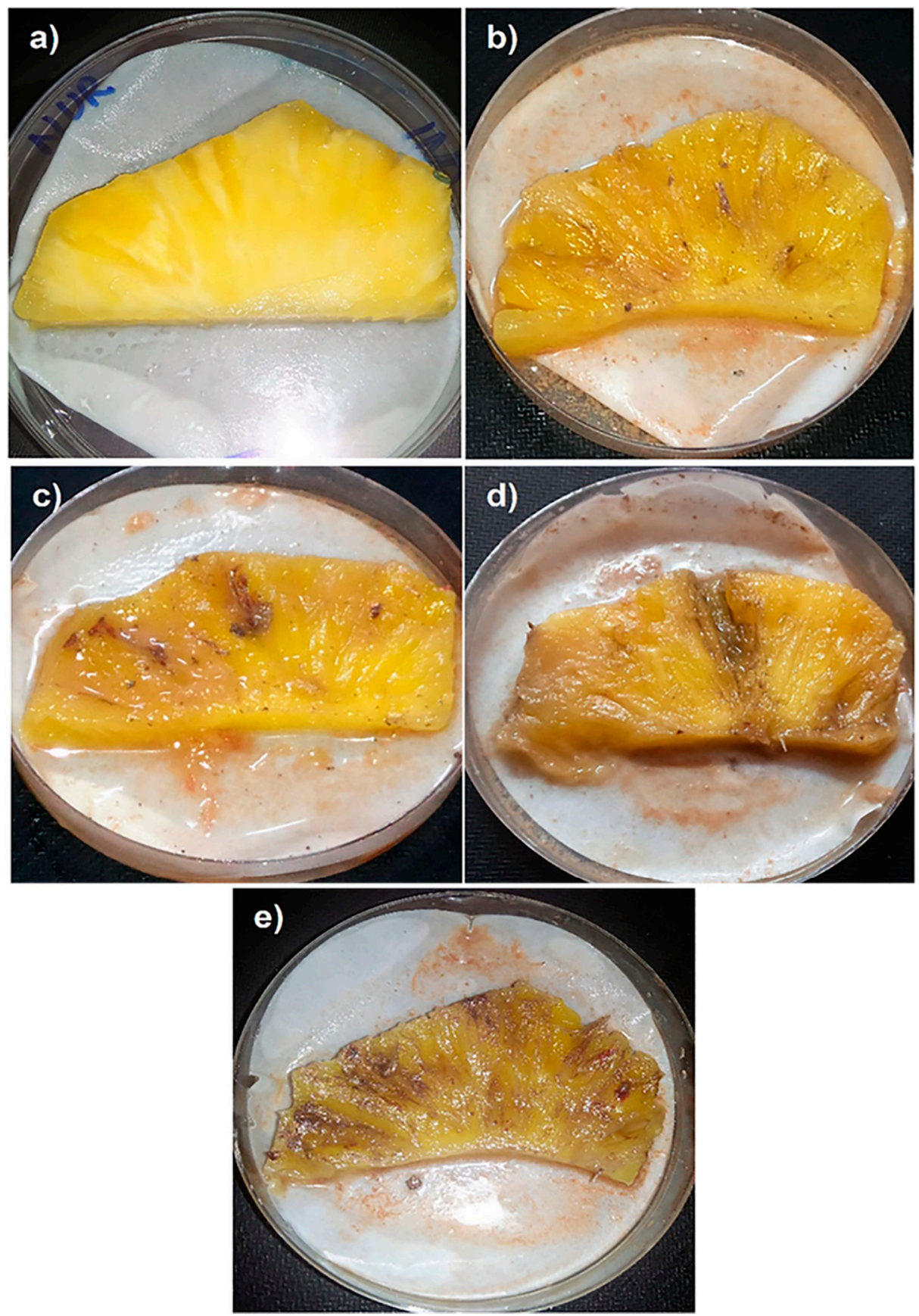

Figure 5. The disease rating of localized lesions of pineapple fruitlets (rating 0-4). (a) Disease rating 0 ; (b) disease rating 1; (c) disease rating 2; (d) disease rating 3; (e) disease rating 4. 
Table 5. The disease rating of localized lesions of pineapple fruitlets (developed from this study).

\begin{tabular}{cc}
\hline Disease Rating & Description \\
\hline 0 & $\begin{array}{c}\text { No symptom } \\
1\end{array}$ \\
3 & $\begin{array}{c}\text { Localized lesion area covered } 1-24 \% \text { of } \\
\text { the pineapple } \\
\text { Localized lesion area covered } 25-49 \% \text { of } \\
\text { the pineapple } \\
\text { Localized lesion area covered } 50-74 \% \text { of } \\
\text { the pineapple } \\
\text { Localized lesion area covered }>75 \% \text { of } \\
\text { the pineapple }\end{array}$ \\
\hline
\end{tabular}

3.5. Disease Rating and AUDPC Assessment of Pantoea Stewartii Subspecies Stewartii Inoculated on Jackfruit Varieties, Sweetcorn, Cucumber and Pineapple

At four dpi, the majority of the jackfruit varieties J33 and J34 pulps, inoculated with the Jenderam and Maran isolates, developed symptoms (Figure 6a,b). They showed either reddish discoloration or rusty or bronzing specks with yellowish discoloration (Figures 1 and 2). The symptoms that appeared were similar to the appearance of the infected collected fruits (isolates from the reddish discoloration symptom samples induced a reddish discoloration symptom on the inoculated fruits, and isolates from rusty or bronzing specks with yellowish discoloration induced rusty or bronzing specks with yellowish discoloration on the inoculated fruits) (Table S1). The appearance of symptoms on jackfruit varieties J33 and J34 inoculated with isolates from Muadzam Shah and Ipoh varied, manifesting at around eight to $14 \mathrm{dpi}$. No disease progression was observed on the MS-4-inoculated jackfruits for both varieties (Figure 6a,b). On the other hand, disease symptoms progressed faster in jackfruit varieties J33 and J34 when inoculated with the isolate JEN-14. No symptoms were observed on the isolated jackfruit variety J39 within $14 \mathrm{dpi}$ (Figure 6c). Furthermore, no disease symptoms appeared in the control group of all jackfruit varieties.

The inoculated sweetcorn showed symptoms of pale or yellowish-green leaf streaks on the nine-week-old seedlings (Figure $3 \mathrm{~b}$,d and Figure $7 \mathrm{a}$ ) but no symptoms showed on the two-week-old seedlings (Figures $3 \mathrm{a}$ and $7 \mathrm{~b}$ ). Like the jackfruit varieties J33 and J34, it took only four days for the nine-week-old seedlings to show Stewart's wilt symptoms when inoculated with isolates from Jenderam and Maran. In contrast, consistent results of symptom appearance were observed at seven and eight dpi when inoculated with the Muadzam Shah and Ipoh isolates (Figure 7a). In addition, the nine-week-old seedling that was inoculated with the isolate JEN-4 reached the maximum disease rating of 9 at 11-14 dpi, while the other isolates from Jenderam and Maran maximized at around a 3-8 rating at eight to $14 \mathrm{dpi}$, and isolates from Muadzam Shah and Ipoh maximized with a consistent rating of 2-3 at 11-14 dpi (Figure 7a). In contrast, the slowest and the lowest disease rating was in MS-4-inoculated seedlings (nine weeks old), only showing symptoms at $14 \mathrm{dpi}$ with a disease rating of 1 .

At seven and eight dpi, cucumber and pineapple inoculated with the Jenderam and Maran isolates showed symptoms of a reddish discoloration (Figures 4 and 8a) and localized lesions on the surface of the fruitlet (Figures 5 and $8 b$ ), respectively. The majority of the Muadzam Shah and Ipoh isolates elicited symptoms at 13 dpi in cucumber and at nine dpi in pineapple. Likewise, similar to J33, J34 and sweetcorn (nine weeks old) inoculation, the isolate JEN-14 still progressed faster than other isolates in cucumber and pineapple, whereas the isolate MS-4 was the lowest, with no disease progression (Figure 8a,b). No disease symptoms appeared in the control sweetcorn, cucumber, and pineapple. 
The AUDPC value, based on the disease rating for J39 and two-week-old sweetcorn seedlings, was not performed due to no symptom being elicited after these inoculations (Figures $6 \mathrm{c}$ and $7 \mathrm{~b}$ ). The AUDPC value, based on the disease rating calculated from initial to $14 \mathrm{dpi}$ on the inoculated jackfruit varieties (J33 and J34), sweetcorn (nine weeks old), cucumber, and pineapple, revealed that the isolate JEN-14 was the most aggressive by more than double, compared to other isolates $(p<0.05$; Figure 9$)$. The results illustrate how highly significant the isolate JEN-14 was compared with the rest of the isolates $(p<0.05$; Figure 9). Despite the isolate MS-4 being observed as the least aggressive, based on the disease rating progression (Figure 6a,b, Figures 7a and 8a,b), not much significant difference was found between the isolate MS-4 and other isolates from Muadzam Shan, Ipoh, and several Jenderam isolates (Figure 9, $p<0.05$ ). We can also see that the median values of isolates from Jenderam and Maran were around twice the median of isolates from Muadzam Shah and Ipoh (except for the isolate MS-4) (Figure 9). Therefore, it can be inferred that the isolate JEN-14 was more aggressive than the other 27 jackfruit-bronzing isolates collected around Peninsular Malaysia.

\subsection{Koch's Postulates on Jackfruit Varieties, Sweetcorn, Cucumber and Pineapple}

The isolation of the inoculated jackfruit varieties, sweetcorn, cucumber, and pineapple revealed P. stewartii subsp. stewartii, except on J39 (no symptom and no bacterial colony) and two-week-old seedlings (no symptom) (15 dpi). The spread-plate method of inoculated jackfruit varieties (except on J39), sweetcorn, cucumber, and pineapple produced bacteria colonies resembling $P$. stewartii subsp. stewartii morphology (lemon yellow color, Figure 10a) and were further subcultured; they showed positive P. stewartii subsp. stewartii identification (Figure 10b). The subcultured bacterial colonies were tested further using biochemical tests, which showed positive $P$. stewartii subsp. stewartii identification (Table S2), namely, the appearance of the red-pink color on Gram staining (Figure 10c); no appearance of the blue-purple color developed within 5-10 s was recorded; oxidase results were negative (Figure 10d); a clear zone formed around the line of bacterial growth and this showed positive hydrolysis of starch (Figure 10e). Nutrient gelatin media from all isolates liquefied, indicating positive results (Figure 10f); a negative motility test was seen for all isolates as the inoculation line was still confined to the stab line. There were no color changes after Kovac's reagent was added to the SIM media, which remained yellow, and the indole production test was negative (Figure 10g). PCR amplification of bacterial colonies from all isolation of inoculated fruits/seedlings (except J39) each produced a 920 bp amplicon (Table S2 and Figure 10h). 
a)
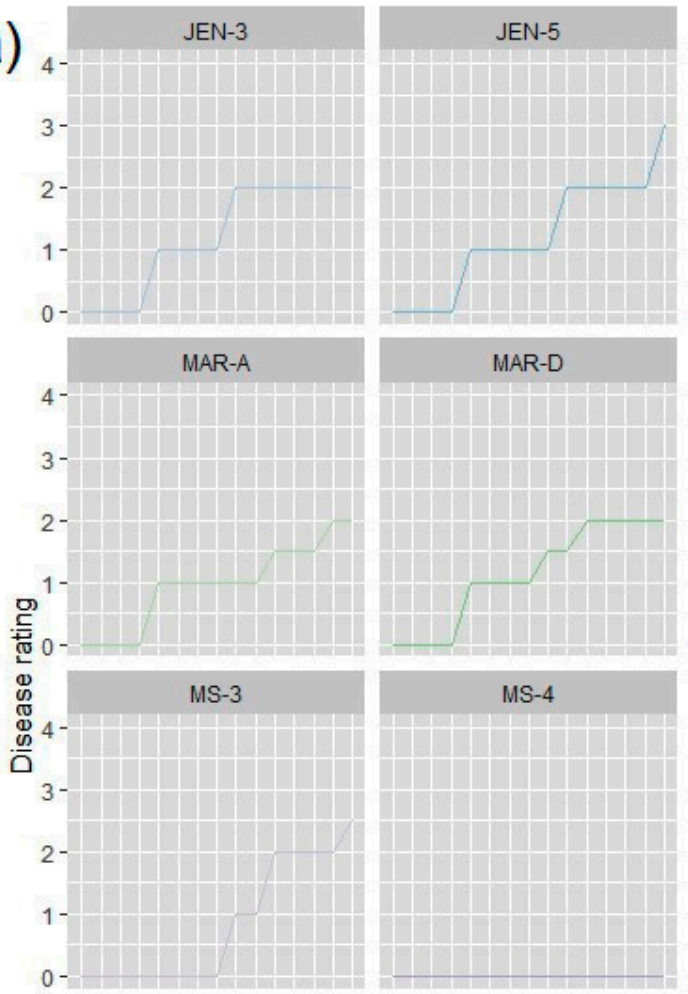

MS-4

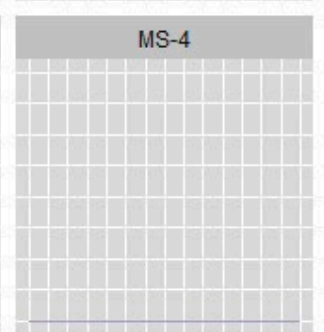

IPOH-5

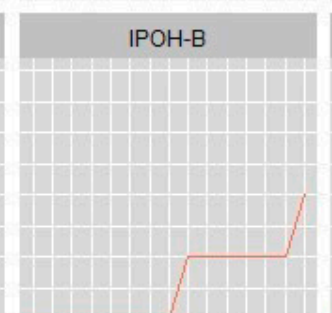

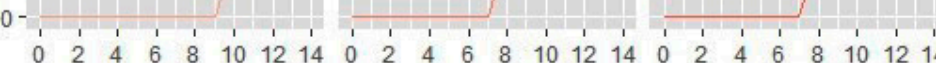
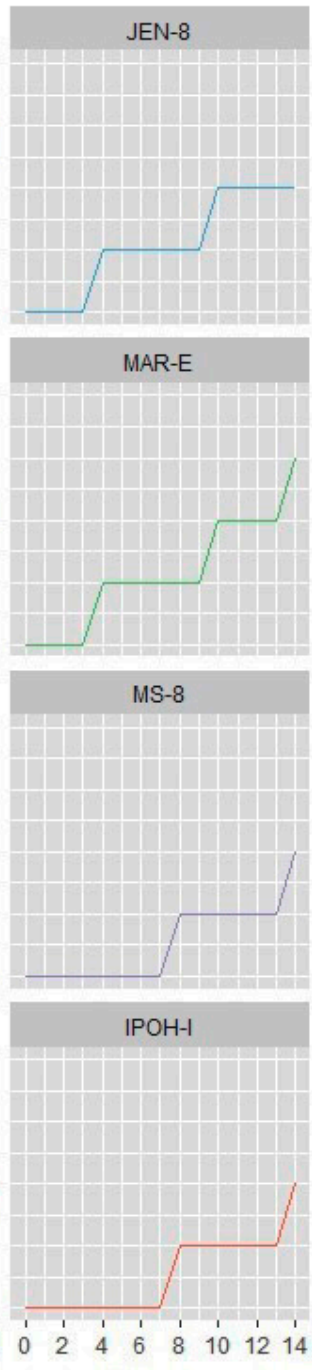

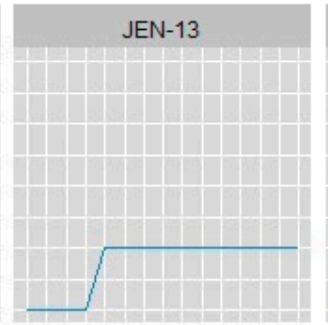

MAR-F

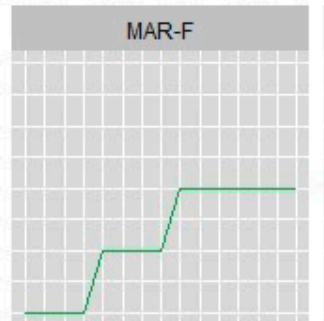

MS-B
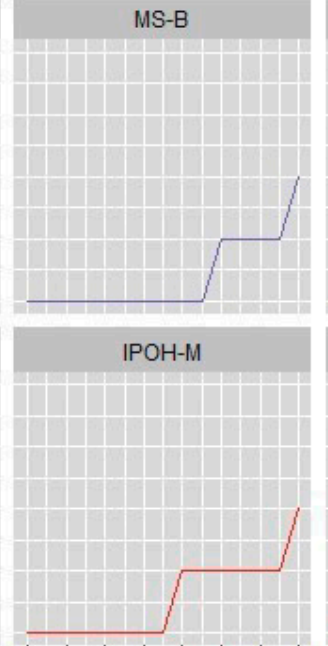

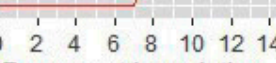
Days post inoculation
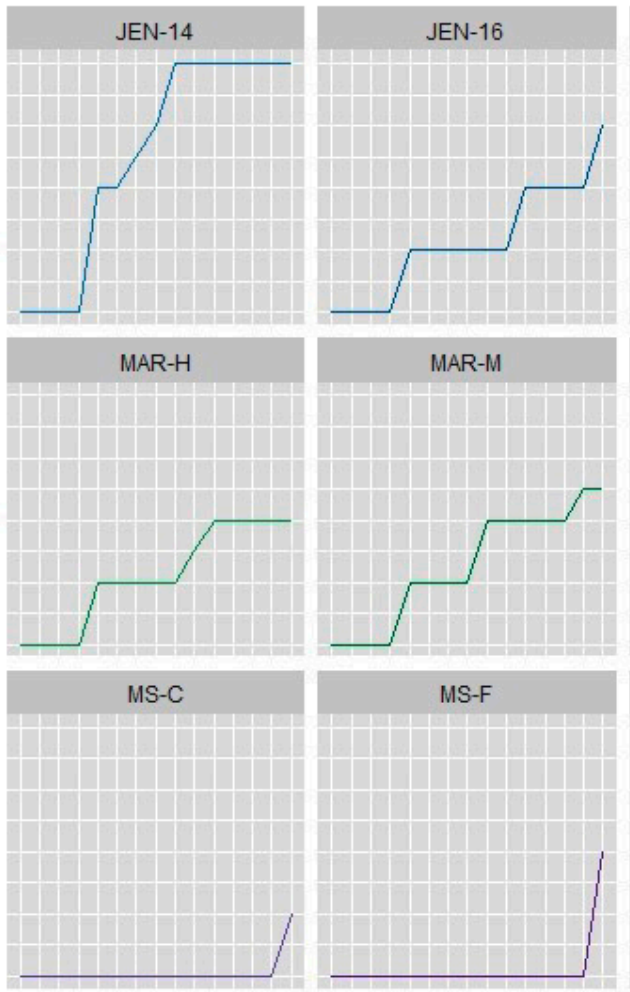

$\mathrm{IPOH}-\mathrm{S}$

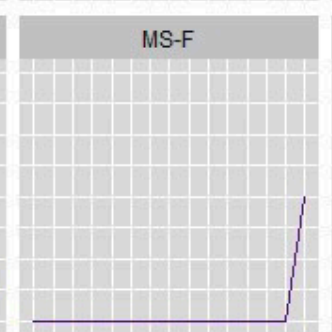

$\mathrm{IPOH}-\mathrm{V}$
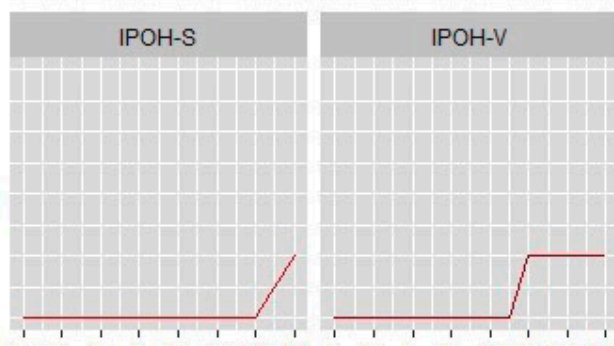

\begin{tabular}{lllllllllllllllll}
\hline & 1 & 1 & 1 & 1 & 1 & 1 & 1 & 1 & 1 & 1 & 1 & 1 & 1 & 1 & 1 \\
0 & 2 & 4 & 6 & 8 & 10 & 12 & 14 & 0 & 2 & 4 & 6 & 8 & 10 & 12 & 14
\end{tabular}

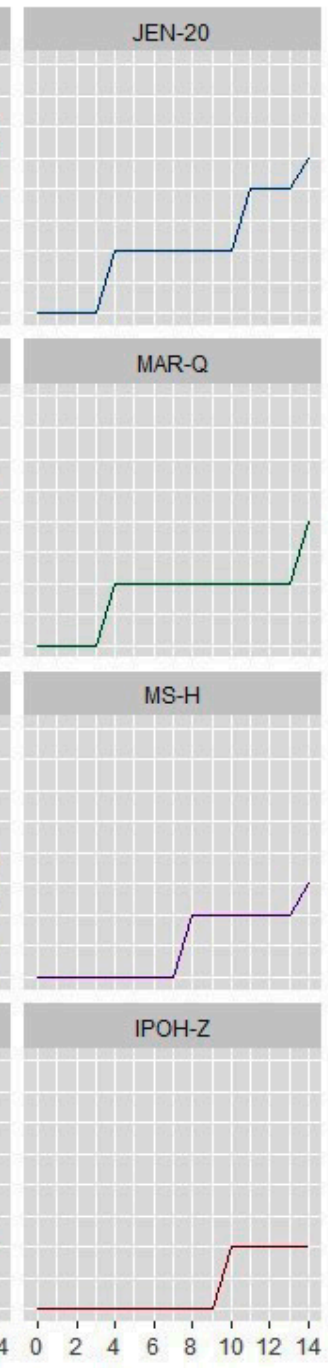

Figure 6. Cont. 
b)

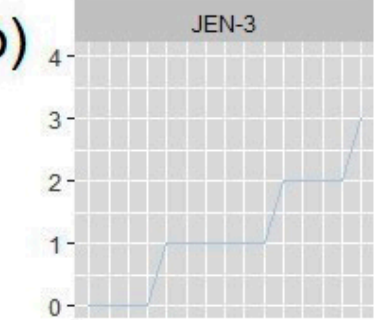

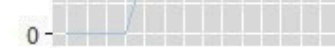

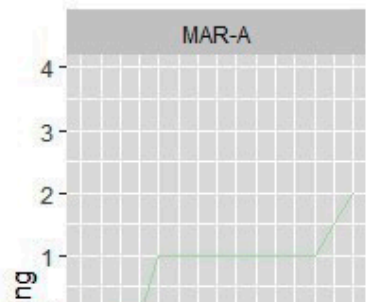

空 $0-$

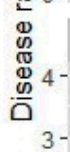

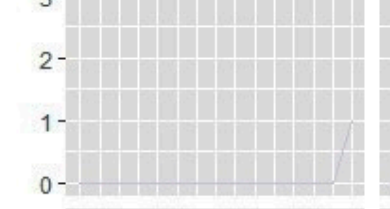

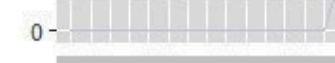

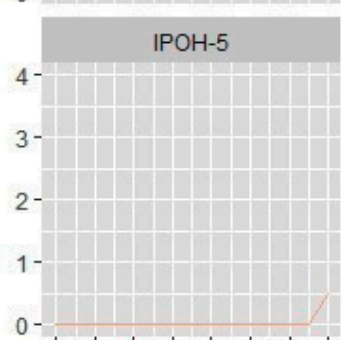

$\begin{array}{lllllllllllllllllllllll}0 & 2 & 4 & 6 & 8 & 10 & 12 & 14 & 0 & 2 & 4 & 6 & 8 & 10 & 12 & 14 & 0 & 2 & 4 & 6 & 8 & 10 & 12\end{array}$
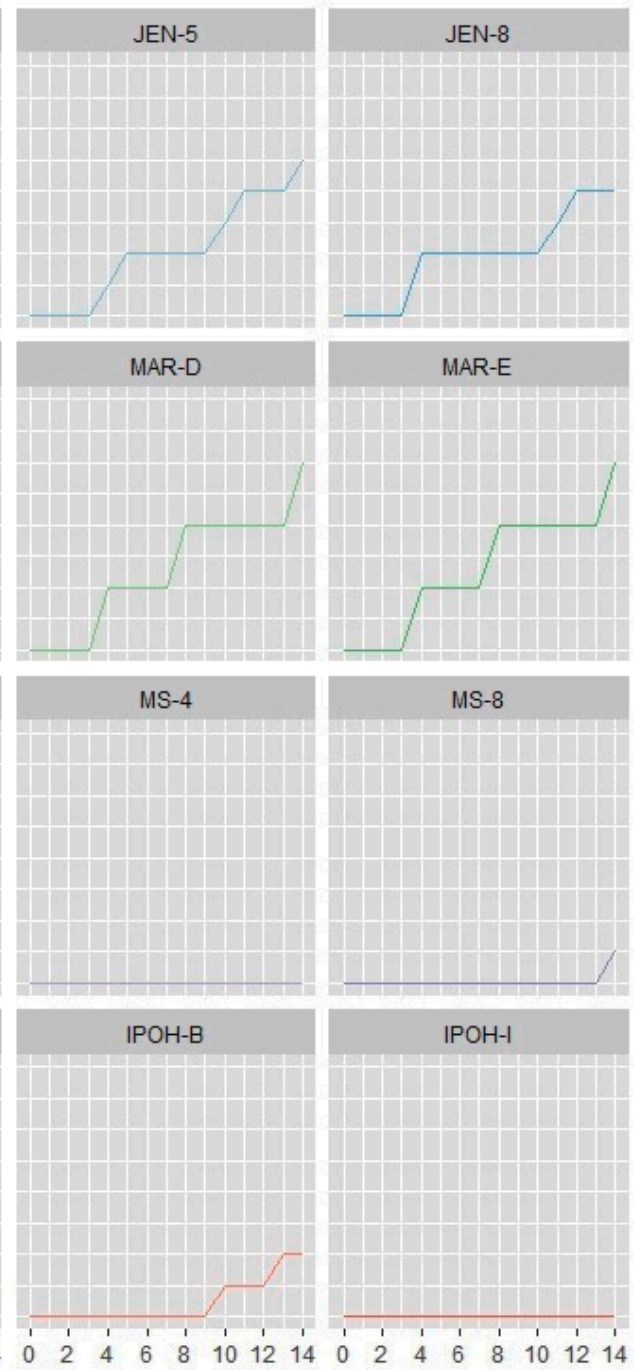
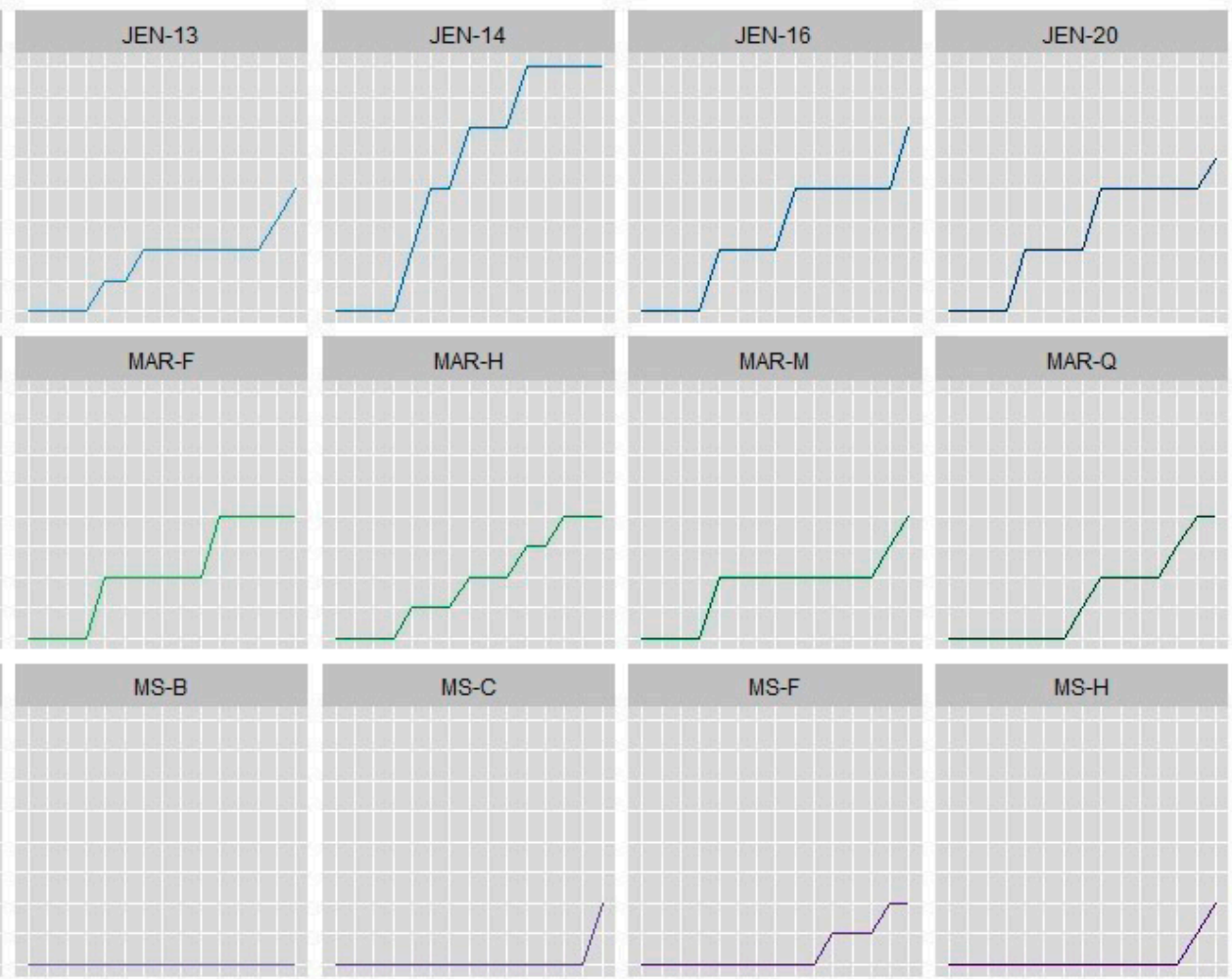

IPOH-M
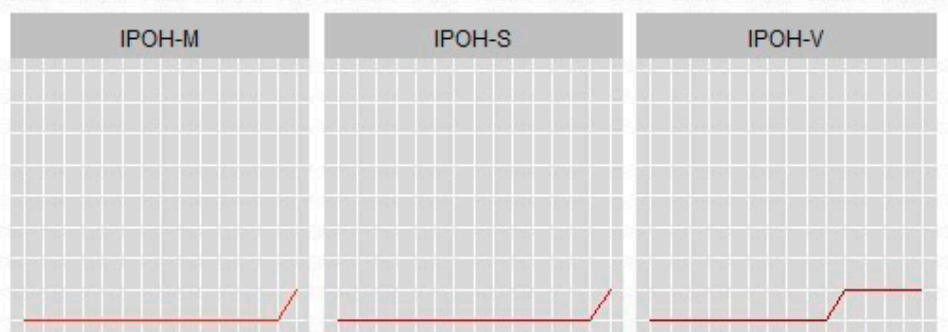

Days post inoculation

\section{Figure 6. Cont.}



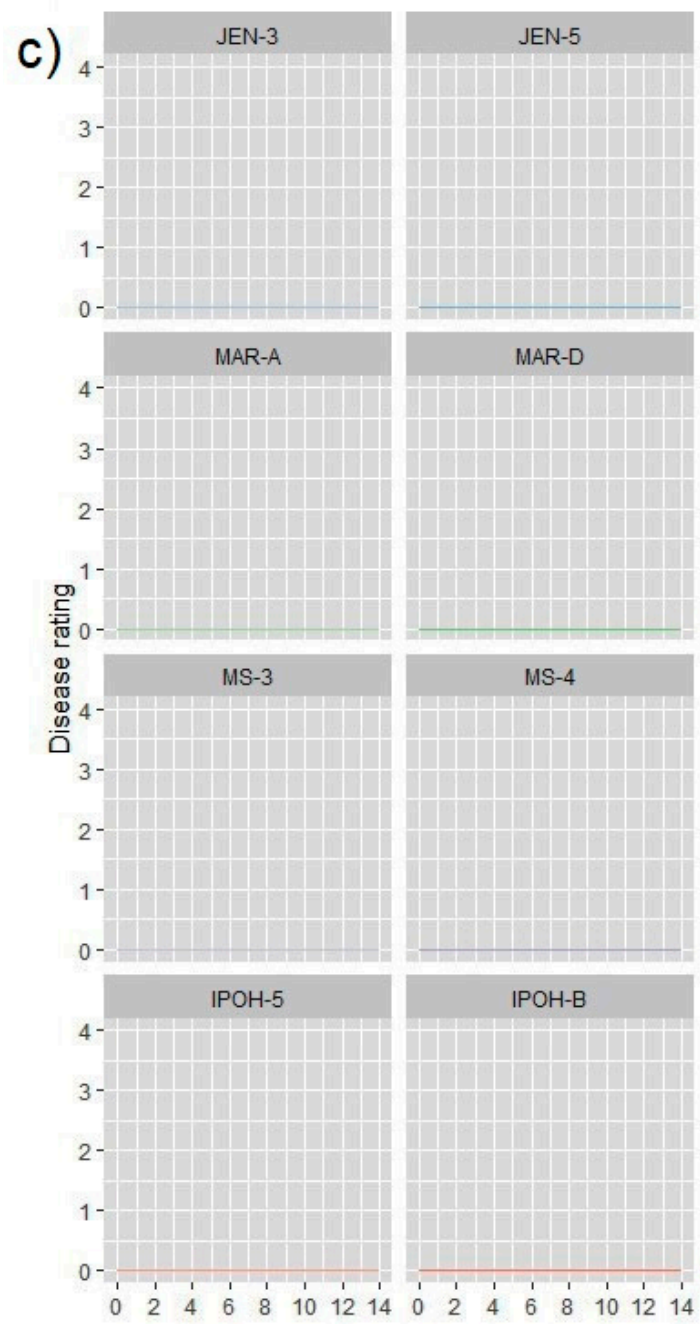

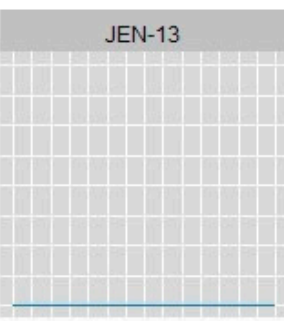

MAR-F
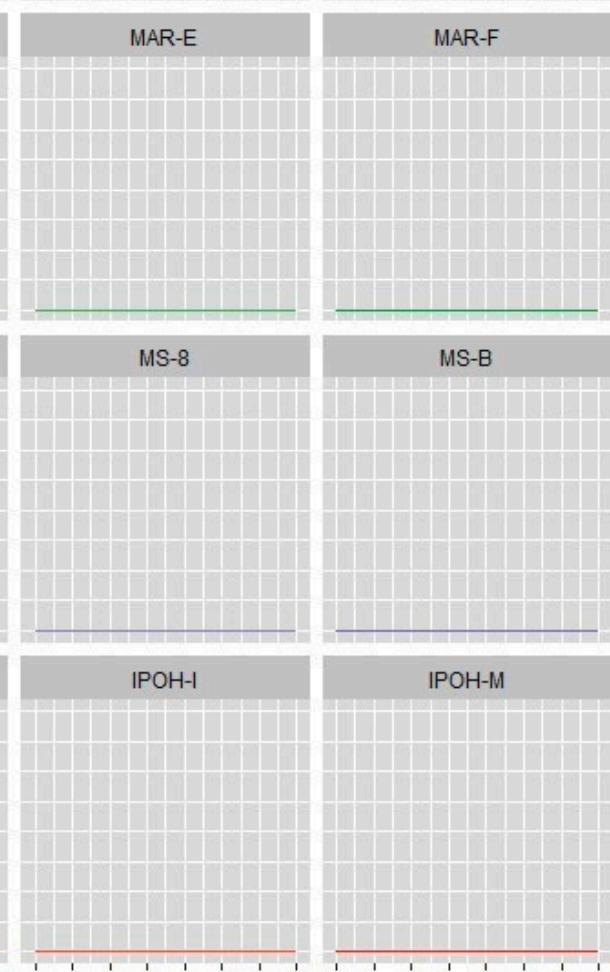

MS-B

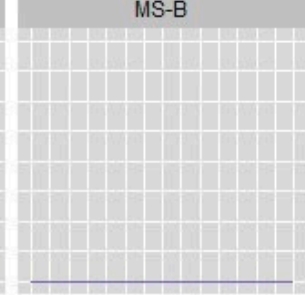

IPOH-M

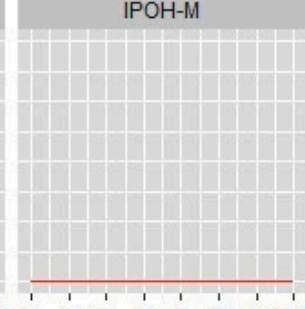

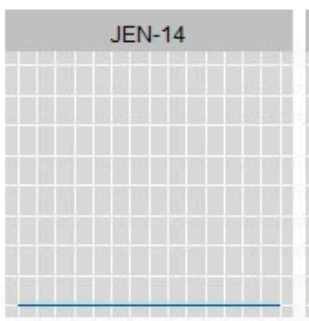

MAR-H

$\begin{array}{llllll}2 & 4 & 6 & 8 & 10 & 12\end{array}$

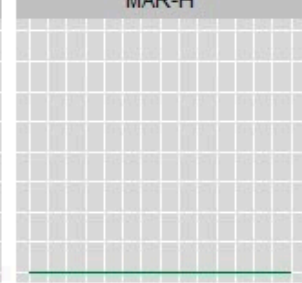

MS-C
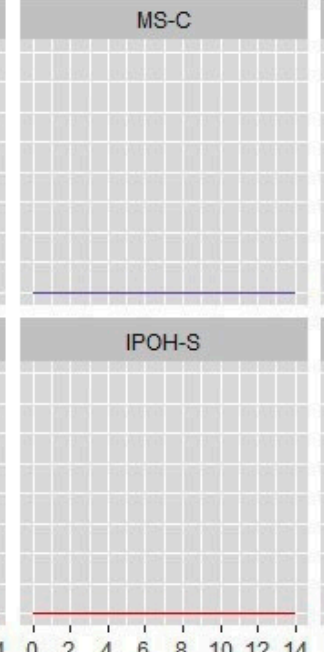

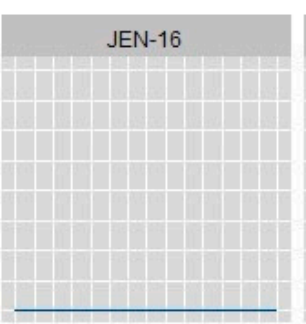

MAR-M
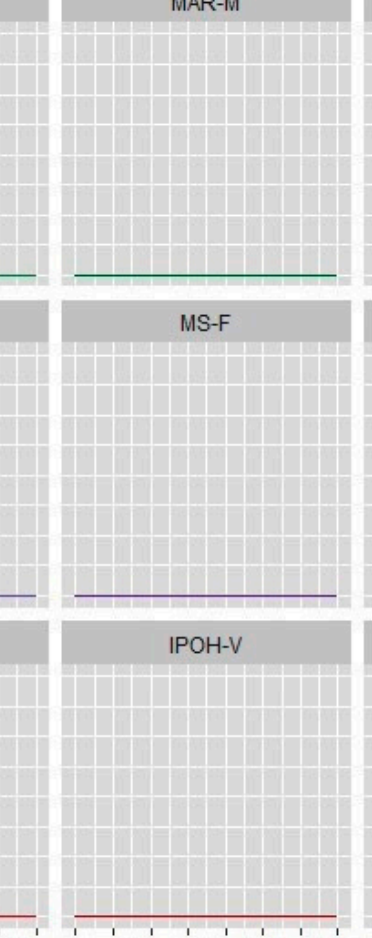

MS-F
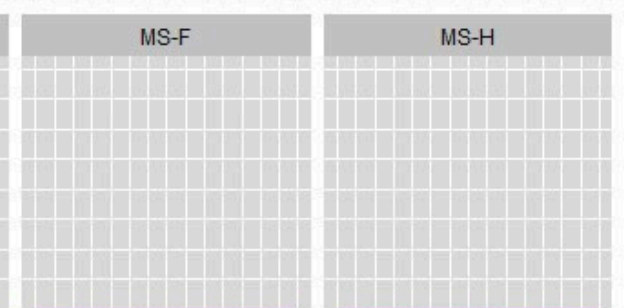

IPOH-Z

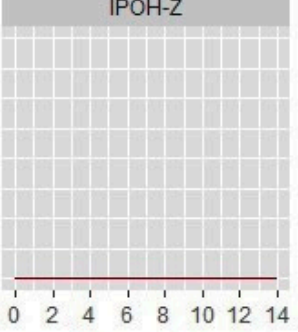

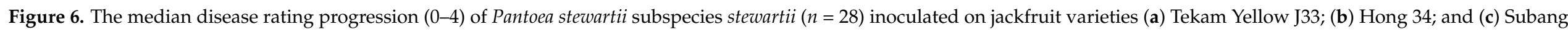

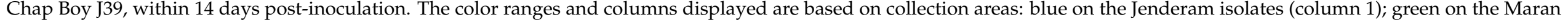
isolates (column 2); purple on the Muadzam Shah isolates (column 3); and red on the Ipoh isolates (column 4). 
a)

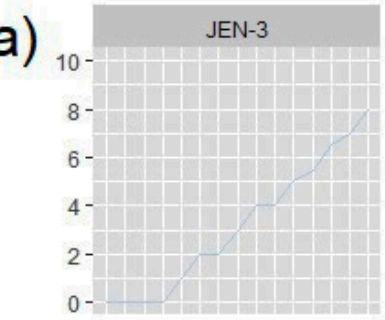

MAR-A

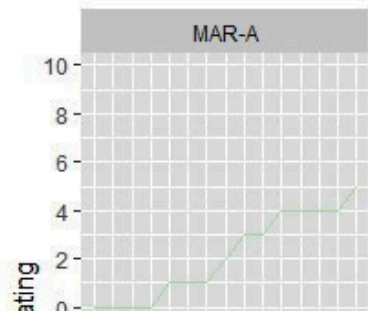

कृ ${ }^{2-}$

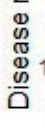

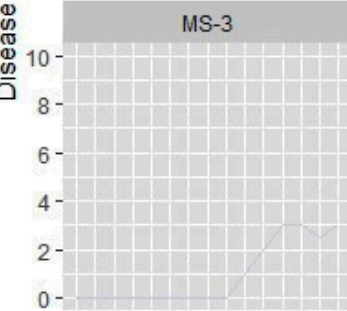

$0-$

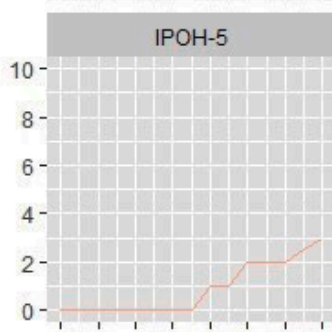

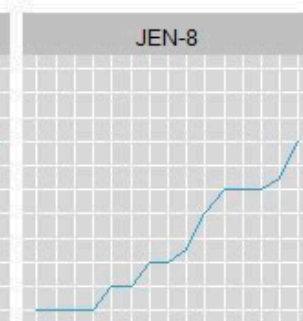

MAR-E

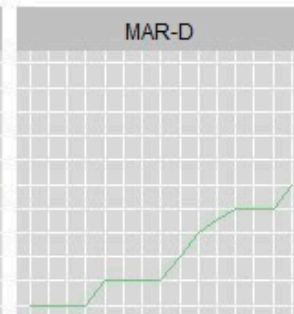

MS-4

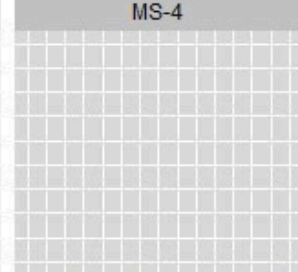

IPOH-B
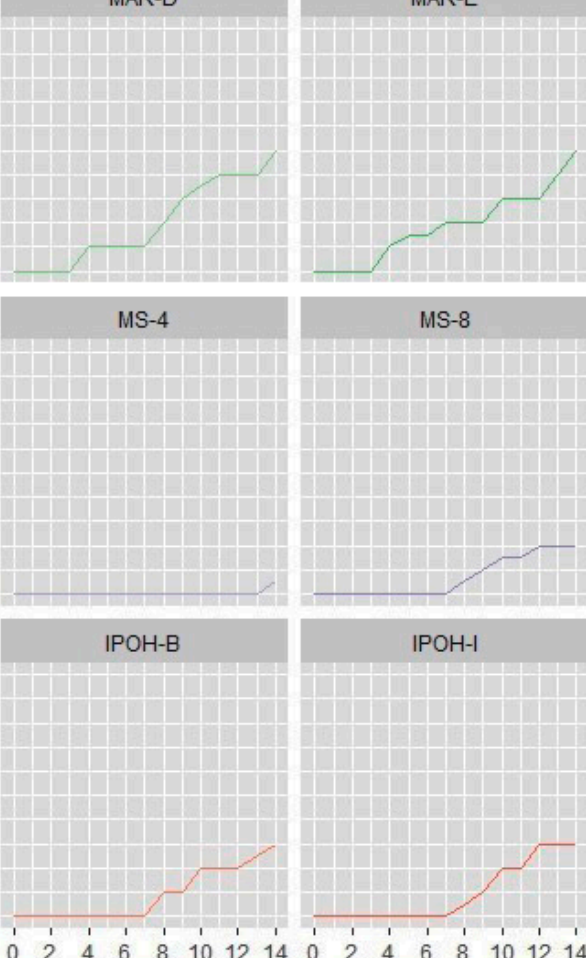

MS-8

IPOH-I

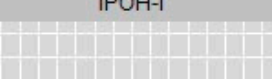

+ +

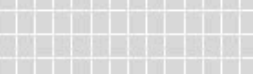

$\sqrt{2}$

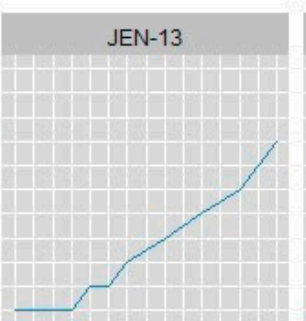

MAR-F
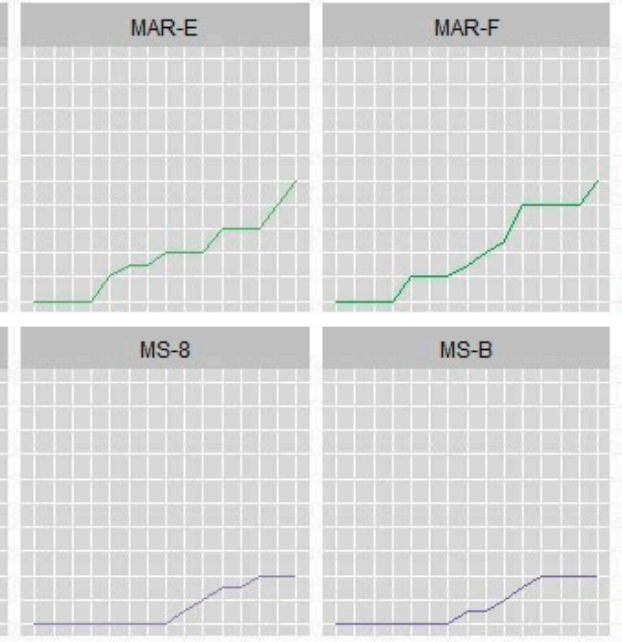

MS-B

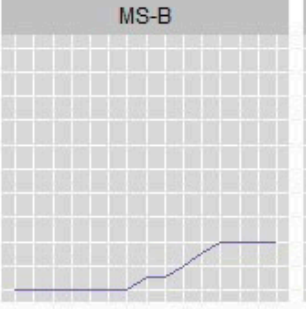

IPOH-M
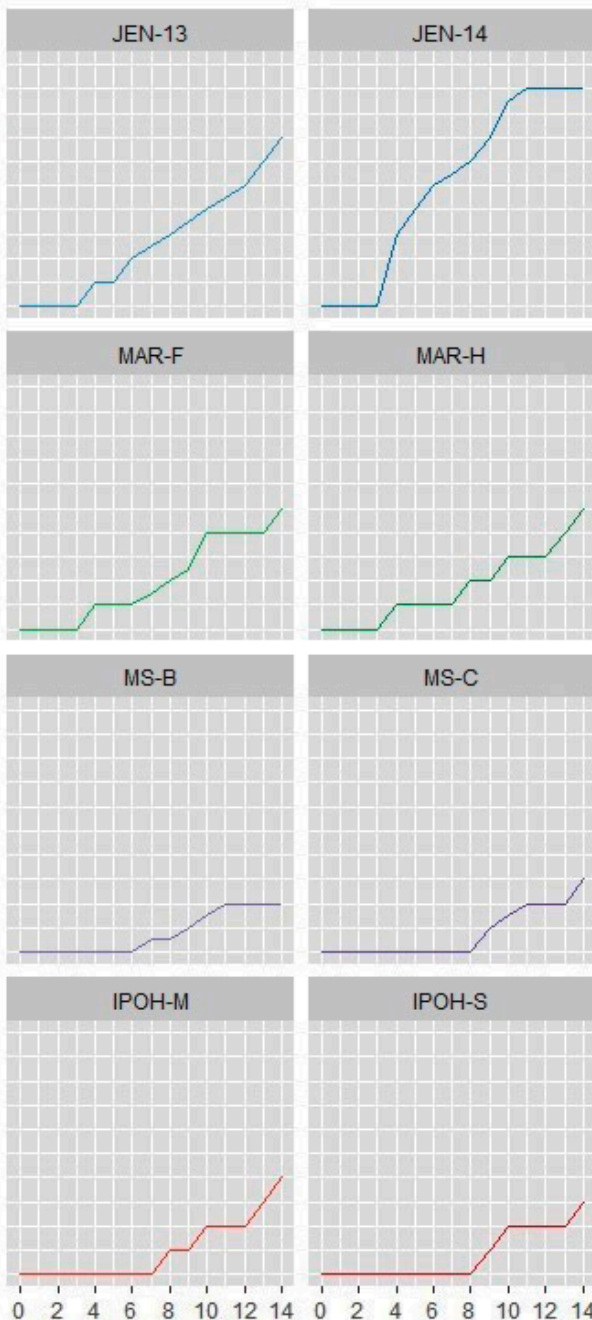

MAR-H

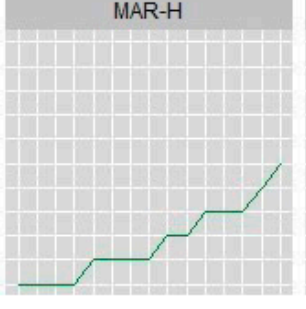

MS-C

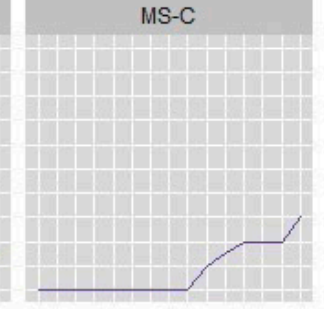

IPOH-S
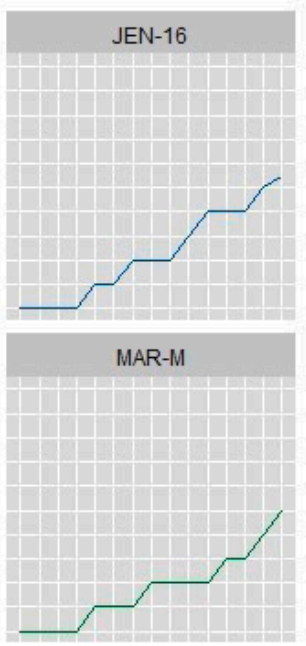

MS-F

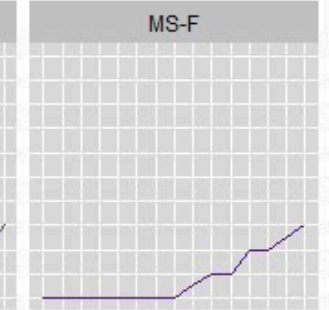

IPOH-V
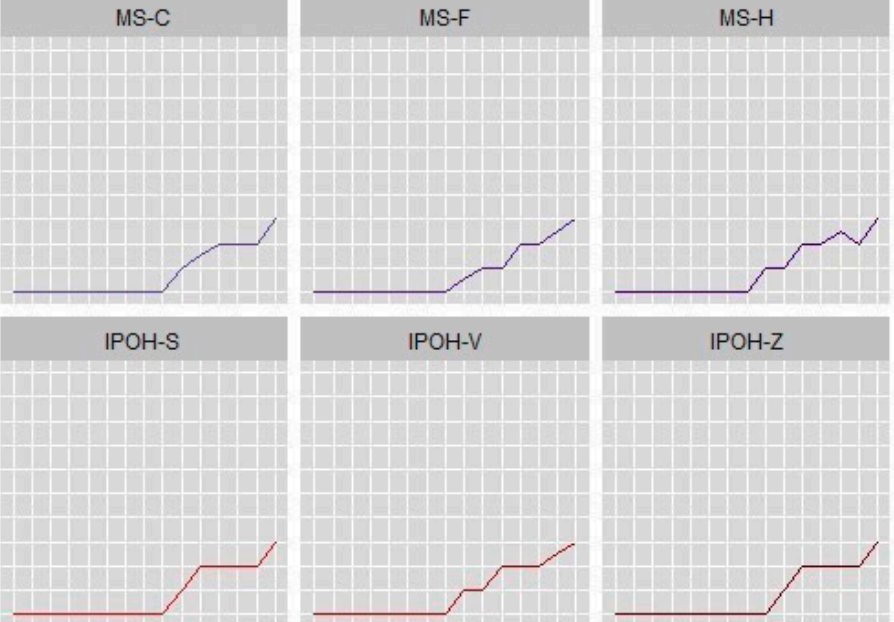

$\begin{array}{lllllllll}1 & 2 & 4 & 6 & 8 & 10 & 12 & 14\end{array}$ Days post inoculation

Figure 7. Cont. 
b)
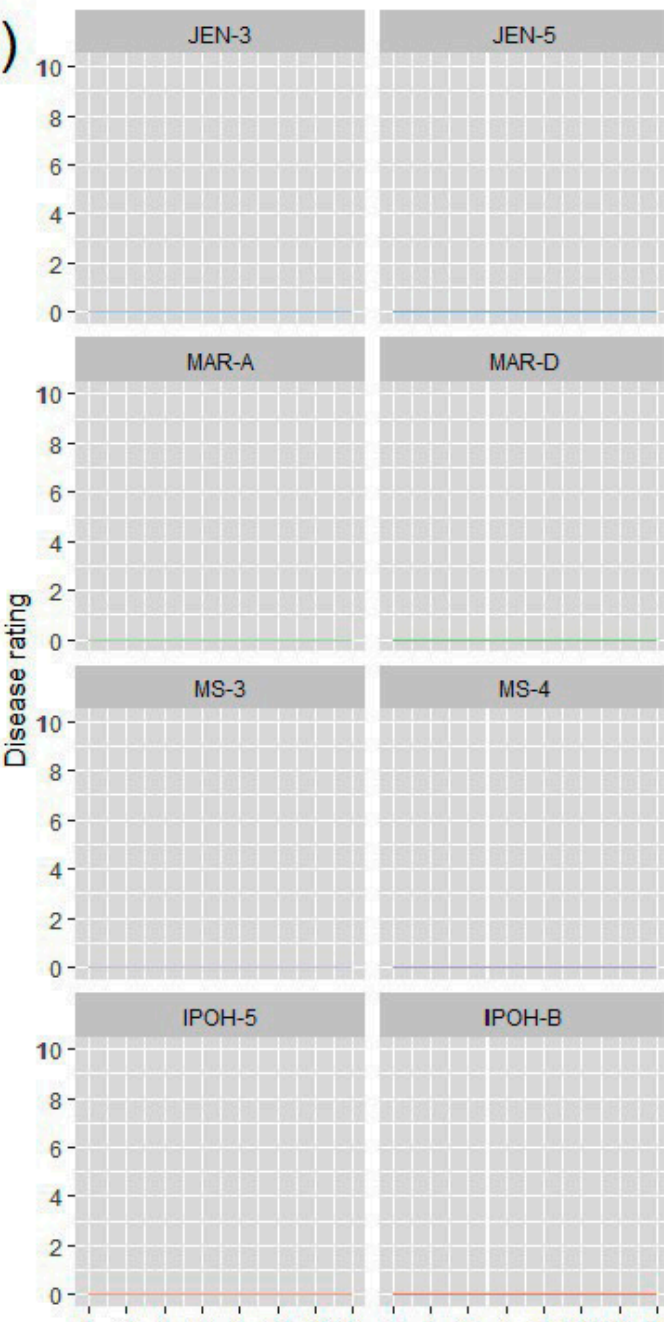

MAR-D
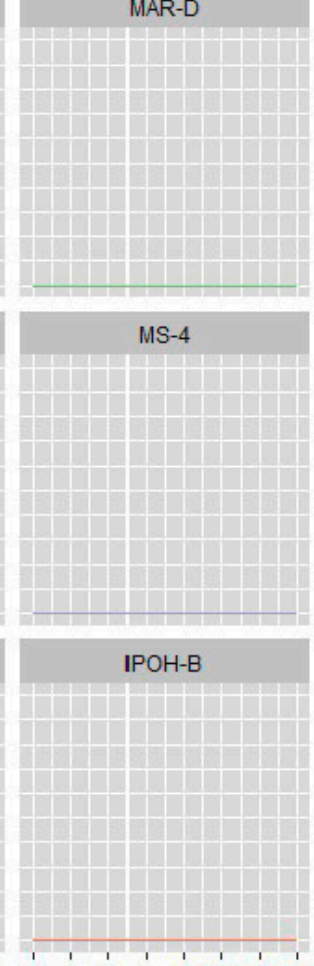

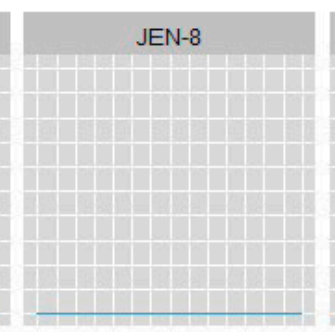

MAR-E

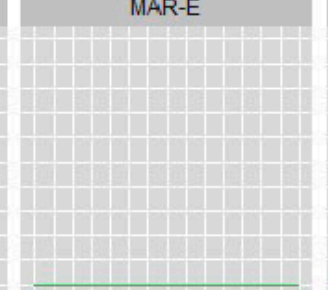

MS-8

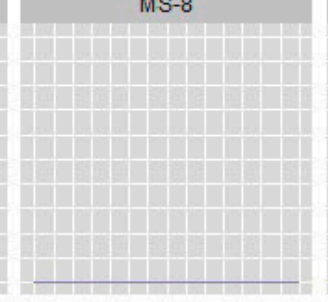

IPOH-I

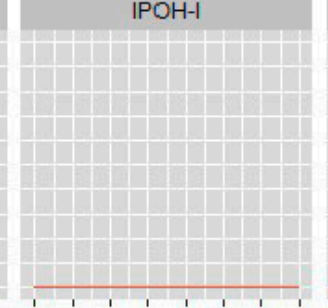

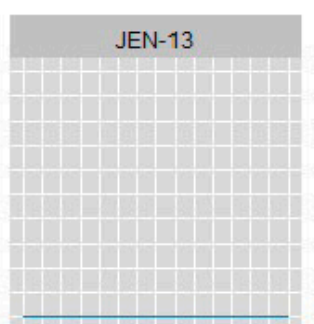

MAR-F
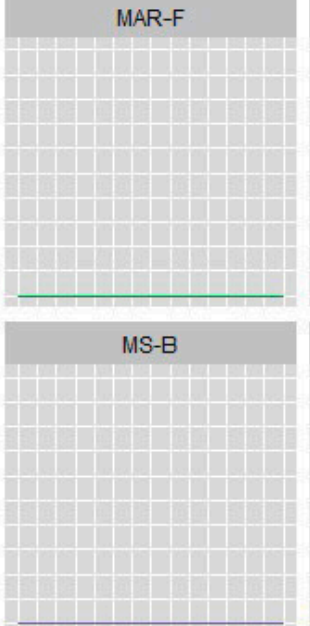

IPOH-M

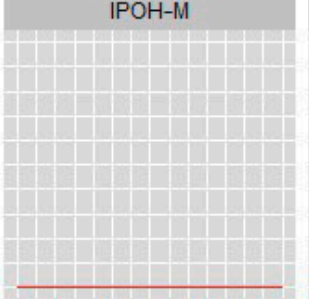

$\begin{array}{llllll}2 & 4 & 6 & 8 & 10 & 12\end{array}$
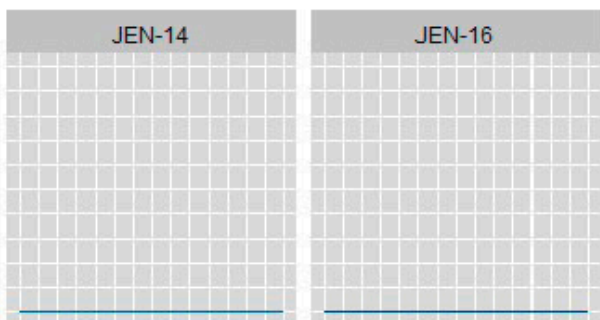

MAR-M
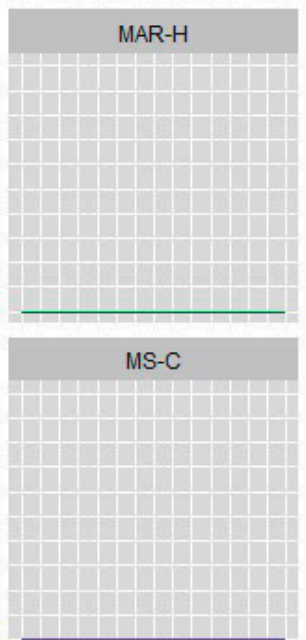

$\mathrm{IPOH}-\mathrm{S}$

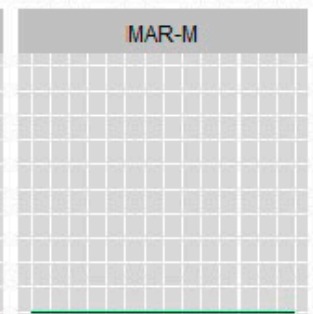

MS-F

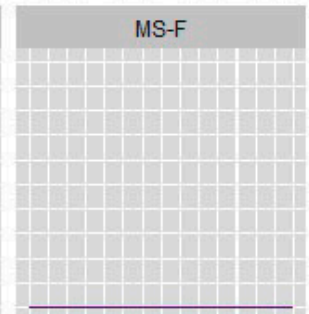

IPOH-V
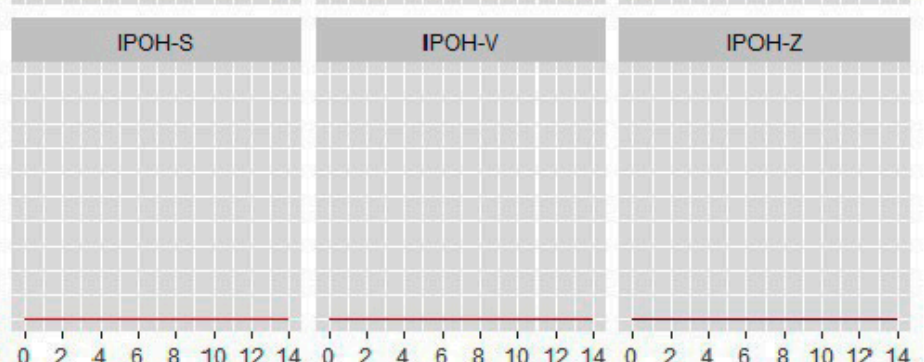

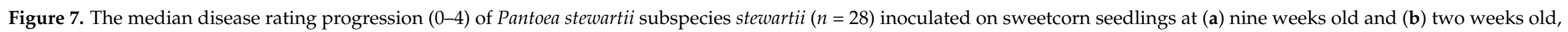

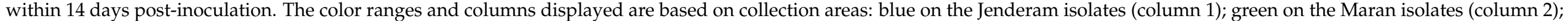
purple on the Muadzam Shah isolates (column 3); and red on the Ipoh isolates (column 4). 
a)

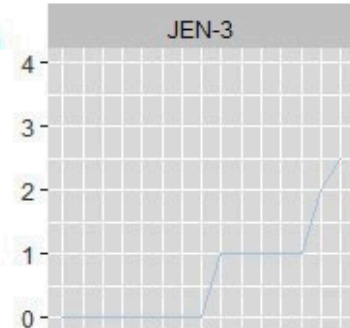

$0-$

MAR-A

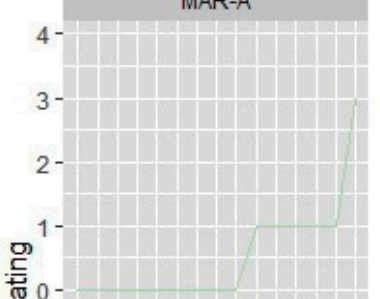

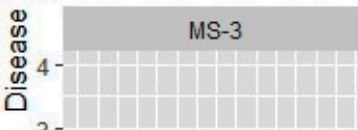

3-

2-

$1-$

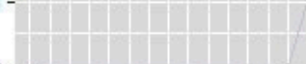

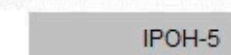

$4-$

3-

$2-$

$1-$

$0-1,1,1,1,1,1$,

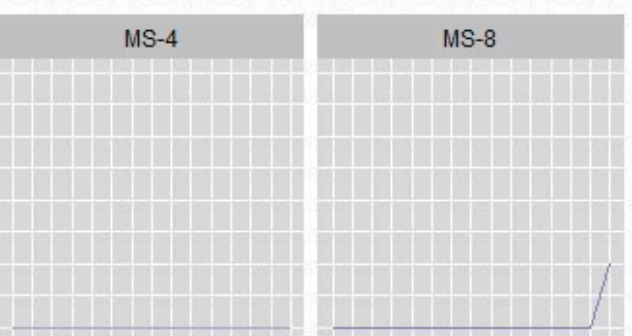

IPOH-B
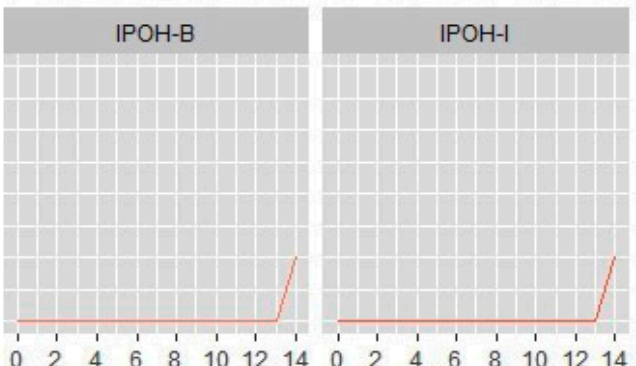

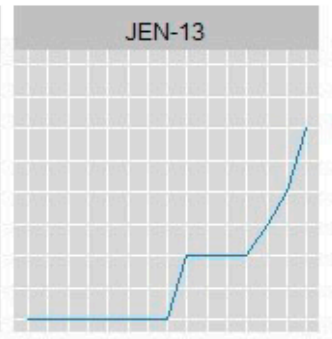

MAR-F

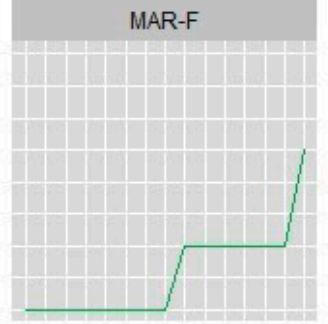

MS-B

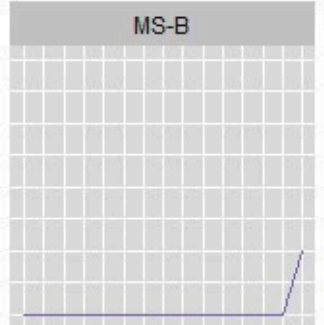

IPOH-M
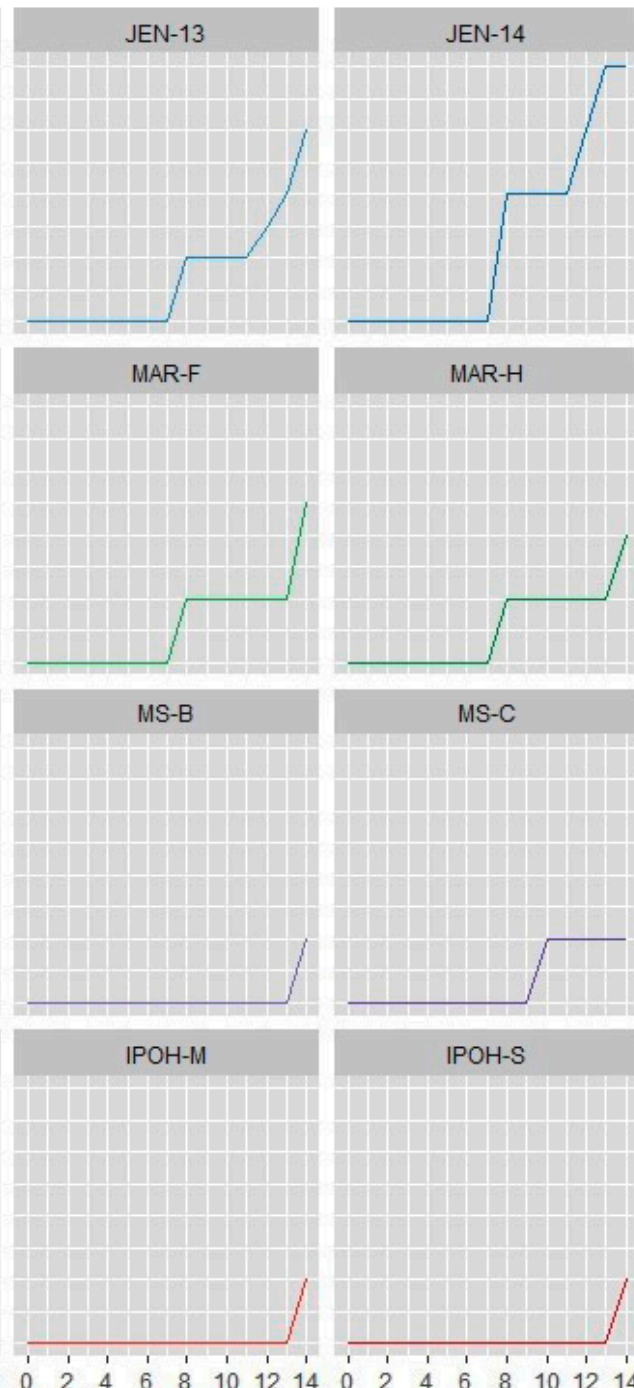

MAR-H

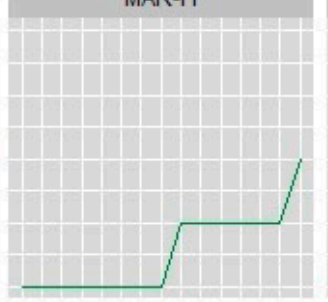

MS-C

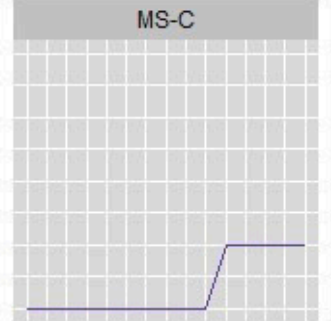

$\mathrm{IPOH}-\mathrm{S}$
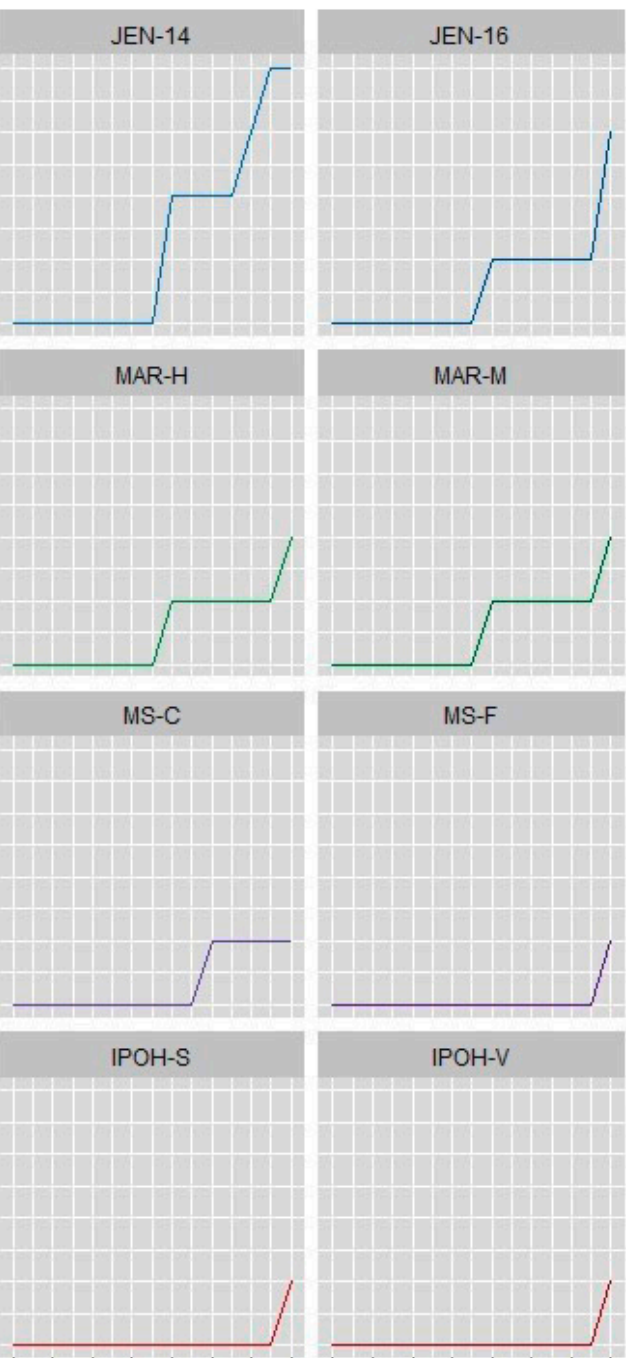

MAR-M

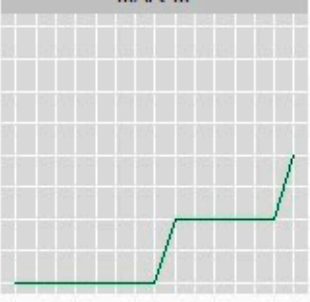

MS-F

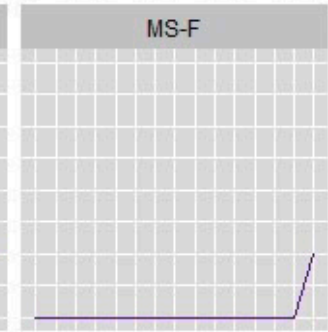

IPOH-V

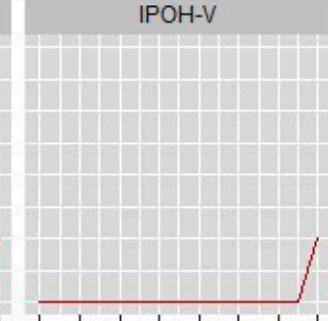

$\mathrm{IPOH}-\mathrm{Z}$

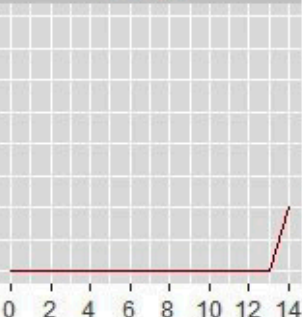

Days post inoculation

Figure 8. Cont. 

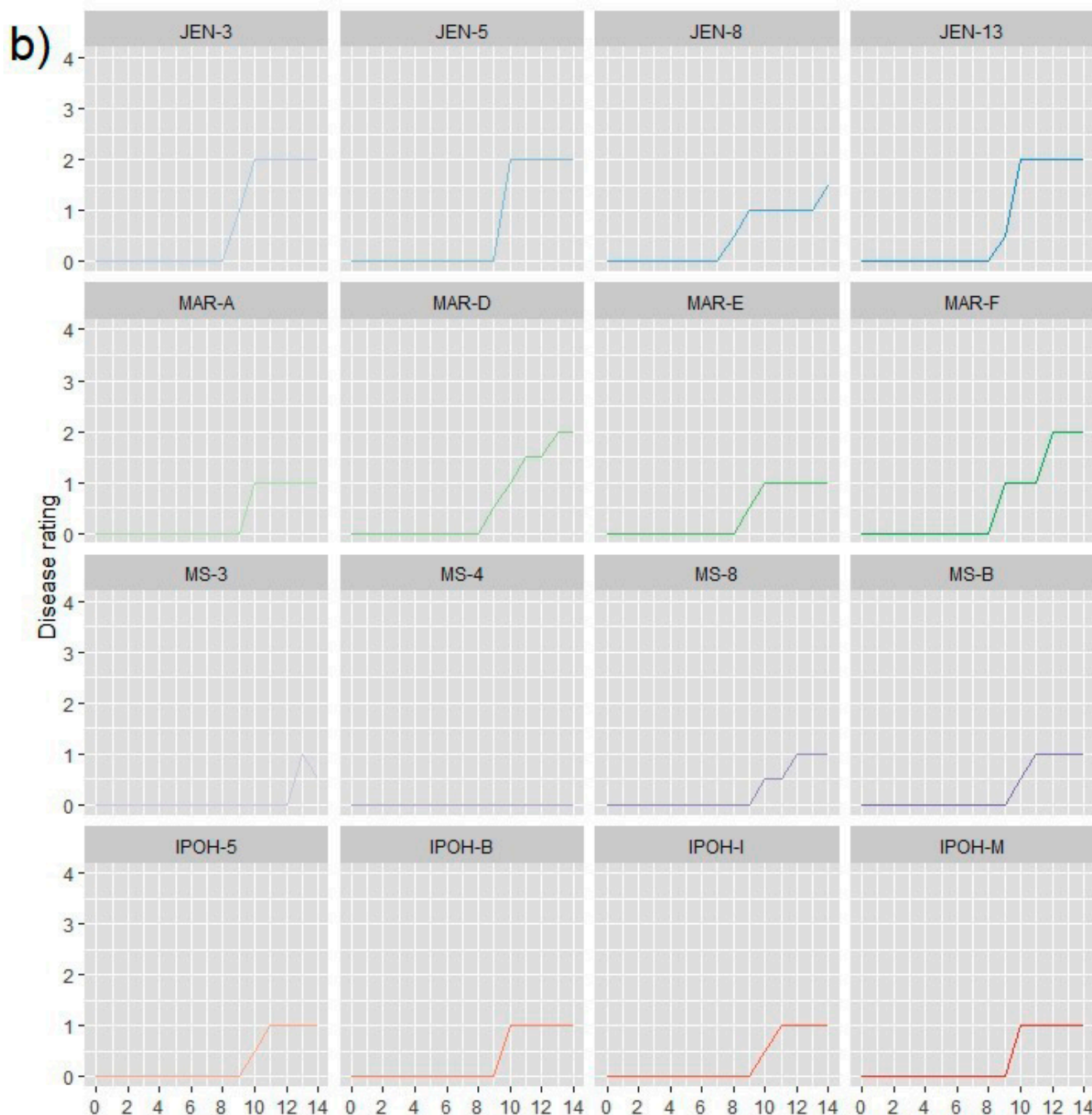

IPOH-M

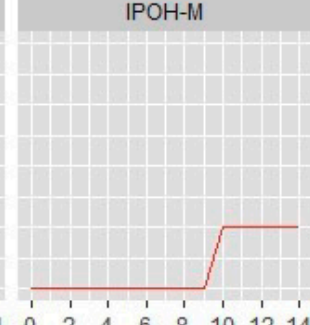
Days post inoculation

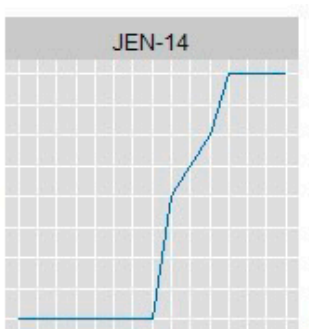

MAR-H

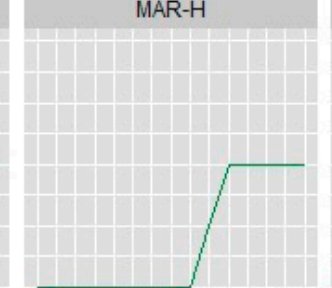

MS-C

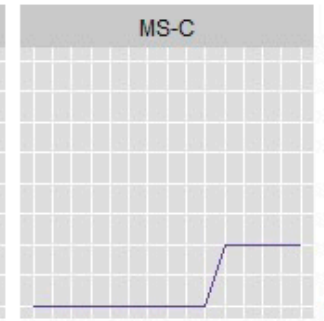

IPOH-S
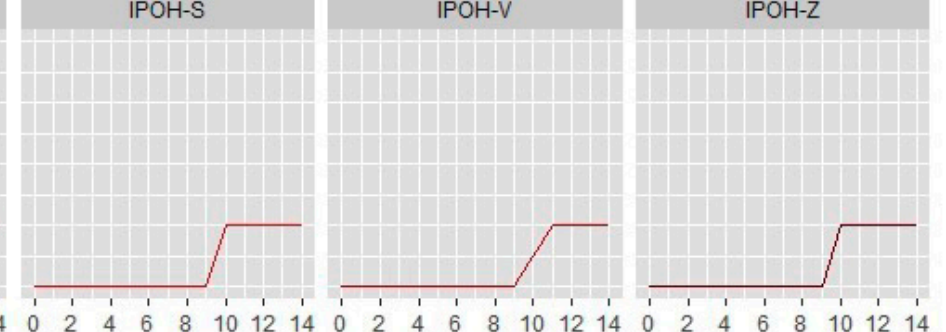

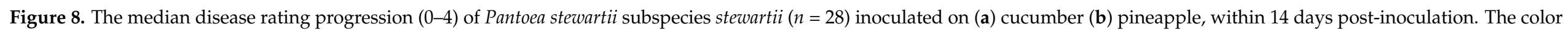

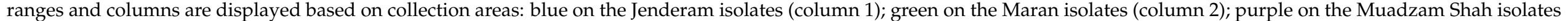
(column 3); and red on the Ipoh isolates (column 4). 


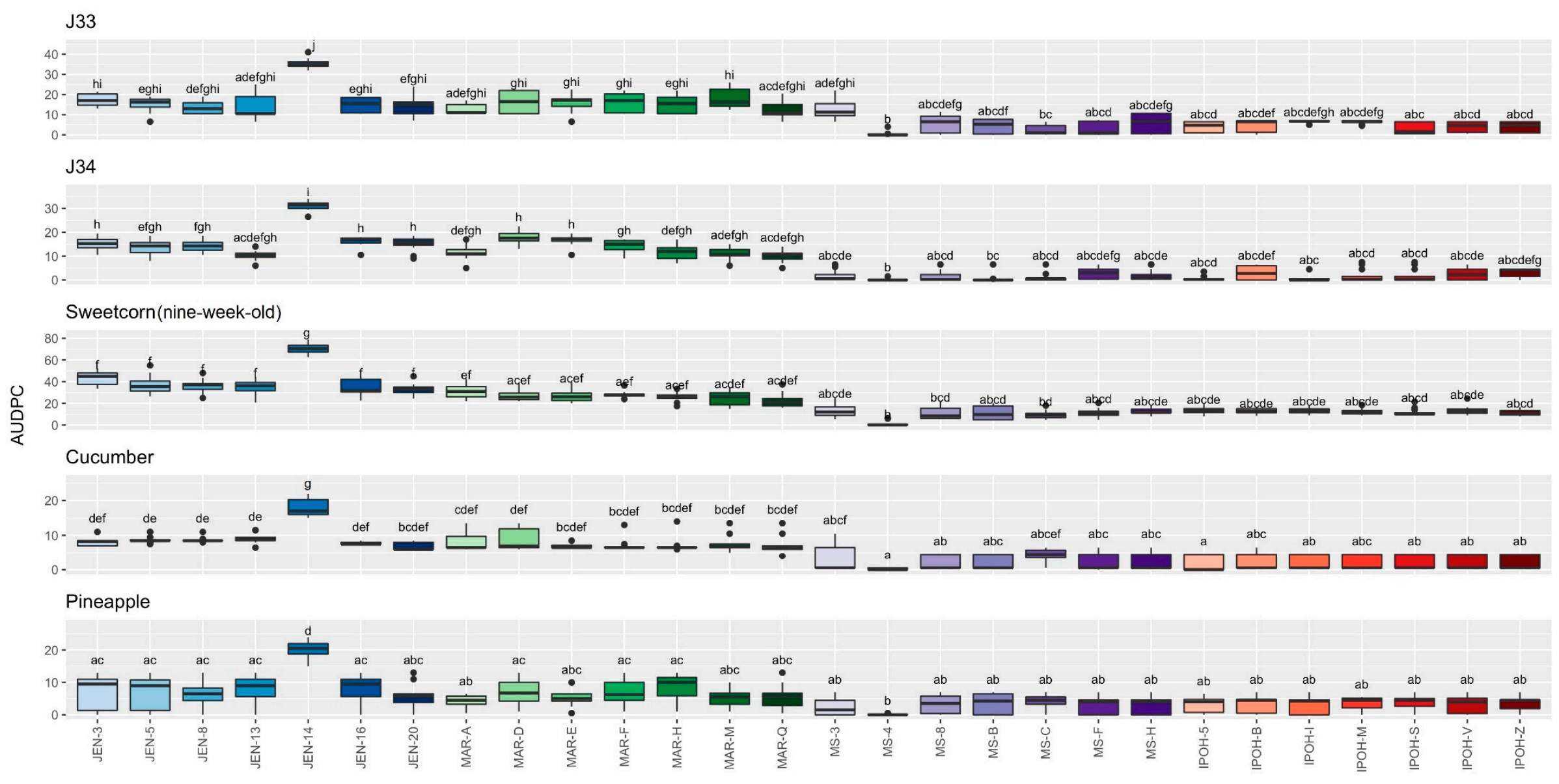

Isolate

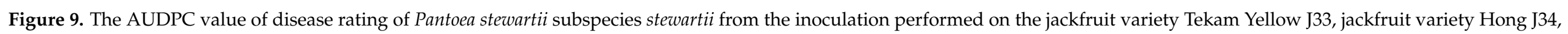

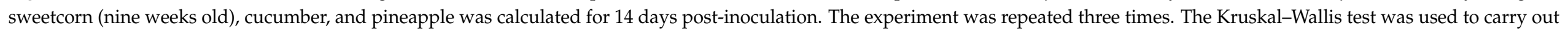

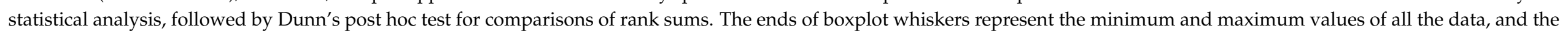

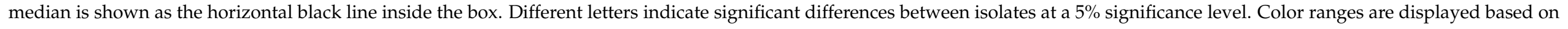
collection areas: blue on the Jenderam isolates; green on the Maran isolates; purple on the Muadzam Shah isolates; and red on the Ipoh isolates. 

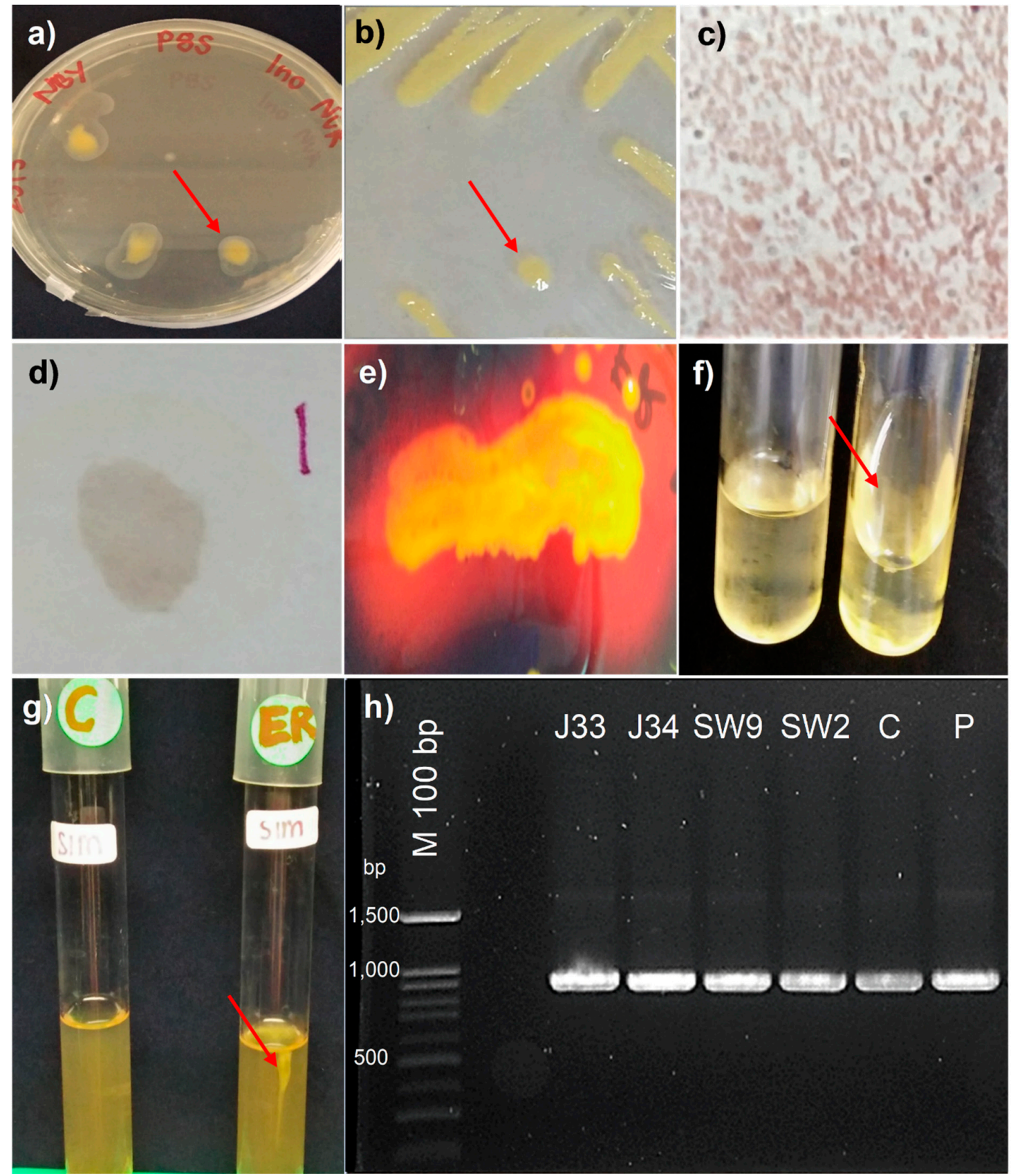

Figure 10. Koch's postulates to identify the bacterial isolates from inoculated jackfruit varieties, sweetcorn, cucumber, and pineapple. (a) Colony morphology of bacterial isolate from inoculated pineapple (with isolate MS-8) via the spread-plate method on an NBY agar; (b) subcultured colonies' morphology isolated from inoculated jackfruit variety J33 (with isolate MAR-D) on a King's B agar medium; (c) Gram-staining of the bacterial isolate from inoculated jackfruit variety J34 (with isolate JEN-3); (d) Kovacs oxidase test of the bacterial isolate from inoculated cucumber (with isolate IPOH-I); (e) starch hydrolysis of the bacterial isolate from inoculated nine-week-old sweetcorn seedlings (with isolate MAR-F); (f) gelatin liquefaction of bacterial isolate from inoculated cucumber (with isolate IPOH-I), control (left); (g) indole production and motility test (SIM media) of the bacterial isolate from inoculated two-week-old sweetcorn seedlings (with isolate MAR-E), control (left); (h) gel electrophoresis showing representative bands of the PCR product of the bacterial isolate from inoculated fruits/seedlings (with isolate JEN-14) from the 16S-23S internally transcribed spacer (ITS) region. The size of the DNA ladder (M) used was 100bp (GeneDireX, Inc.) The amplification fragments were 920 bp (J33: jackfruit variety Tekam Yellow J33; J34: jackfruit variety Hong J34; SW9: nine-week-old sweetcorn seedlings; SW2: two-week-old sweetcorn seedlings; C: cucumber; P: pineapple). 


\section{Discussion}

Data from the pathogenicity tests on the jackfruit varieties showed the same characteristic symptoms of fruit bronzing for the jackfruit varieties J33 and J34. However, no symptom was observed for 14 days on variety J39. Based on the AUDPC value between the three varieties, J33 was the most susceptible, followed by J34, and J39 was the most resistant. Previous findings on these 28 isolates confirmed the presence of $h r p$ (a virulence and pathogenicity gene) and a positive HR on tobacco of P. stewartii subsp. stewartii causing jackfruit-bronzing disease [8]. The type III secretion system (T3SS) protein and hrp gene are the main pathogenicity and virulence factors for P. stewartii subsp. stewartii [55-57], where this $h r p$ gene encodes the T3SS and plays a vital role in plant pathogenic bacteria, eliciting disease in susceptible plants.

The authors of [58] have suggested that exopolysaccharides (EPSs) produced by plant pathogenic bacteria can avoid or delay the activation of plant defenses. However, when tested under in vitro conditions, many EPSs were produced and activated only when the culture medium of $P$. stewartii subsp. stewartii contained fermentable sugar, such as glucose and sucrose [59]. The results suggested that nutrient availability could regulate the expression and activation of the hrp gene in plant pathogens [60]. Thus, the nutrient availability of the host is necessary to activate the plant pathogen. Interaction of P. stewartii subsp. stewartii with a living host with high nutrients strengthen the pathogen growth level [59]. Furthermore, [61] reported that J33 and J34 varieties have sweet pulps with $27-30 \%$ brix and $11.6-14.2 \%$ brix, respectively, while J39 has less sweet to moderately sweet pulps, which proved the difference in disease progression.

For sweetcorn inoculation, our results revealed no disease symptoms in the two-weekold seedlings for 14 days (Figure $7 \mathrm{~b}$ ), even though the isolation at $15 \mathrm{dpi}$ resulted in the positive presence and confirmation of $P$. stewartii subsp. stewartii (Table S2). We recommend using older age-stage seedlings as inoculation into young sweetcorn leaves may lead to a false symptom and disease assessment. This scenario was shown in the current study, where the nine-week-old seedlings produced a similar result, an atypical symptom of Stewart's disease, as demonstrated in maize and sweetcorn inoculated with Stewart's wilt pathogen [41,44] and jackfruit-bronzing pathogen [10]. Very young sweetcorn or maize is prone to no lesions or no development of other disease symptoms [41].

The results observed from the inoculation of pineapple showed a similar pattern to that demonstrated by [10], which produced localized rotting symptoms. Unfortunately, the results for the cucumber inoculation obtained from the experiment contradict a study by [10]. The researchers [10] did not observe any results from the inoculation, whereas this current study showed a reddish discoloration symptom similar to bronzing on jackfruit. The symptoms elicited in the cucumbers were similar to cucumber disease caused by Pseudomonas syringae pv. lachrymans, known as angular leaf spot, which causes soft rot and reddish-brown discoloration on and inside the cucumber fruit [62]. Pectobacterium carotovorum subsp. brasiliense, which causes bacterial soft rot in cucumber, also elicited similar symptoms of reddish-brown discoloration in the internal fruit part [63]. As mentioned previously, the T3SS protein and the hrp gene are the main pathogenicity and virulence factors for P. stewartii subsp. stewartii. Further study has confirmed that a T3SS protein of P. stewartii subsp. stewartii, known as WtsE, causes cell death activity and suppresses plant defenses against the non-host plants Arabidopsis thaliana, Nicotiana benthamiana and Beta vulgaris cv. Red Ace Hybrid (beet) [56,57].

Kruskal-Wallis analysis, followed by Dunn's post hoc test of the AUDPC, based on disease rating among isolates, confirmed that only the isolate JEN-14 was highly significant compared with the other 27 isolates. The consistency of the isolate JEN-14 as the most aggressive isolate when inoculated into J33, J34, sweetcorn (nine-week-old sweetcorn), cucumber, and pineapple, as well as the 0-rating disease progression on J39 (resistance variety), may be beneficial and applicable for future use in resistance screening and breeding against jackfruit-bronzing disease. Using the least aggressive isolate may lead to false 
disease breeding evaluation. It may show a similarly low rating when inoculated into susceptible and resistant varieties.

There were differences in the disease progression performance and the AUDPC based on disease ratings according to collection area. Isolates collected from Jenderam and Maran progressed better. They had a higher median than isolates collected from Maran and Ipoh, even though no significant correlation was found among the isolates (except for isolate JEN-14). According to [64], variations in the pathogenicity and aggressiveness of plant pathogens could also arise due to the ecological environment and host diversity. Additionally, bacterial competence and genomic modifications are influenced by stressful environmental conditions and habitat adaptation [65]. Therefore, in further studies on factors besides aggressiveness that contribute to the outbreak of jackfruit-bronzing disease, factors such as soil and environmental conditions (i.e., temperature, relative humidity, and rainfall) should be considered for effective control of jackfruit-bronzing disease in Peninsular Malaysia.

This study documented for the first time the pathogenicity symptoms of P. stewartii subsp. stewartii isolates on jackfruit varieties, sweetcorn, cucumber, and pineapple, based on a disease rating assessment of jackfruit-bronzing disease from the four sites of isolate collection in Malaysia. Our study aids and guides using a pictorial disease-rating reference of $P$. stewartii subsp. stewartii pathogenicity on jackfruit and with the inoculation of cucumber and pineapple, based on visual and image-based assessments. Not only will these pictorial disease rating scales and assessments be valuable in the future for plant breeders but they can also benefit researchers, especially plant pathologists, as they provide more information on the diseases and guides to investigate further how far and how fast jackfruit-bronzing disease has progressed, thus allowing for the development of management control strategies to combat the spread of the disease.

Supplementary Materials: The following are available online at https://www.mdpi.com/article/ 10.3390/agronomy11112113/s1, Table S1: Symptoms of the isolates from the collected infected jackfruit (Artocarpus heterophyllus variety Tekam Yellow J33) from the four infected collection areas and symptoms induced on inoculated jackfruit pulps $(\mathrm{n}=28)$; Table S2: Biochemical and molecular characterization of the isolates isolated from the inoculated jackfruit varieties, sweetcorn nine-weekold seedlings, cucumber and pineapple at 15 days post-inoculation; Figure S1: Image assessment for the area of infected pineapple fruitlet using ImageJ and Figure S2: Image assessment for bronzing and rusty specks with yellowish discoloration of infected jackfruit pulp using ImageJ.

Author Contributions: Conceptualization, S.I.I., G.V., M.T.Y., M.H., D.S.K. and D.Z.; methodology, N.A., S.I.I., G.V., M.T.Y., M.H., D.S.K. and D.Z.; software, N.A. and D.Z.; validation, S.I.I., G.V. and D.Z.; formal analysis, N.A.; investigation, N.A.; data curation, N.A. and D.Z.; writing-original draft preparation, N.A.; writing—review and editing, N.A., S.I.I., G.V., M.T.Y., M.H., D.S.K. and D.Z.; supervision, S.I.I., G.V., D.Z.; project administration, D.Z.; funding acquisition, N.A. and D.Z. All authors have read and agreed to the published version of the manuscript.

Funding: This research was funded by the Ministry of Higher Education of Malaysia (MOHE) through Fundamental Research Grant Scheme (FRGS/1/2018/WAB01/UPM/02/9), GP-IPS/2018/ 9638500, GP-IPM/2016/9494600, SEAMEO SEARCA (https:/ / www.searca.org/, accessed on 10 May 2018) and UPM-SEAMEO SEARCA Joint Scholarship (First author).

Institutional Review Board Statement: Not applicable.

Informed Consent Statement: Not applicable.

Data Availability Statement: Data are available within this manuscript. The data that support the findings of this study are also openly available in (i) Figshare at https:/ / plos.figshare.com/ articles/Pathogenicity_of_i_Pantoea_stewartii_i_subspecies_i_stewartii_i_strains_on_day_14_postinoculation_/12474644, accessed on 10 May 2018, reference number [10.1371/journal.pone.0234350. g005] and (ii) Genbank with the accession codes MK802515, MK802516, MK802517, MK802518, MK802519, MK802520, MK802521, MK802522, MK802523, MK802524, MK802525, MK802526, MK802527, MK802528, MK802529, MK802530, MK802531, MK802532, MK802533, MK802534, MK802535, MK531591, MK802536, MK802537, MK802538, MK802539, MK802540, MK802541. 
Acknowledgments: We thank the staff of the Department of Plant Protection, UPM, for their technical assistance in this study and the Department of Agriculture (DOA), Malaysia, for their support and providing healthy fruits. We would also like to thank K.A. and N.A.I.M.Z. for their insightful discussion and comments. The presented study is part of N.A.'s Master's thesis (UPM, 2020).

Conflicts of Interest: The authors declare no conflict of interest. The funders had no role in the design of the study; in the collection, analyses, or interpretation of data; in the writing of the manuscript, or in the decision to publish the results.

\section{References}

1. Balamaze, J.; Muyonga, J.H.; Byaruhanga, Y.B. Production and utilization of jackfruit (Artocarpus heterophyllus) in Uganda. Afr. J. Food Agric. Nutr. Dev. 2019, 19, 14289-14302. [CrossRef]

2. Department of Agriculture (DOA). Fruit Crops Statistics; Department of Agriculture: Putrajaya, Malaysia, 2019.

3. Department of Agriculture (DOA). Jackfruit (Minimally Processed) Export to Australia; Department of Agriculture: Putrajaya, Malaysia, 2021.

4. Department of Agriculture (DOA). Mengenali Variety Nangka Popular di Malaysia; Department of Agriculture: Putrajaya, Malaysia, 2018.

5. Department of Agriculture (DOA). Mengenali Varieti Nangka Popular di Malaysia; Department of Agriculture: Putrajaya, Malaysia, 2020.

6. Ismail, N.; Kaur, B. Consumer preference for jackfruit varieties in Malaysia. J. Int. Food Agribusiness Mark. 2013, 6, 37-51.

7. Zulperi, D.; Manaf, N.; Ismail, S.I.; Karam, D.S.; Yusof, M.T. First report of Pantoea stewartii subsp. stewartii causing fruit bronzing of jackfruit (Artocarpus heterophyllus), a new emerging disease in Peninsular Malaysia. Plant Dis. 2017, 101, 831. [CrossRef]

8. Abidin, N.; Ismail, S.I.; Vadamalai, G.; Yusof, M.T.; Hakiman, M.; Karam, D.S.; Ismail-Suhaimy, N.W.; Ibrahim, R.; Zulperi, D. Genetic diversity of Pantoea stewartii subspecies stewartii causing jackfruit-bronzing disease in Malaysia. PLoS ONE 2020, 15, e0234350. [CrossRef] [PubMed]

9. Ibrahim, R.; Ismail-Suhaimy, N.W.; Shu-Qing, T.; Ismail, S.I.; Abidin, N.; Hakiman, M.; Karam, D.S.; Ahmad-Hamdani, M.S.; Yusof, M.T.; Zulperi, D. Molecular characterization and phylogenetic analysis of Pantoea stewartii subspecies stewartii causing bronzing disease of jackfruit in Malaysia based on cps and hrp gene sequences. J. Plant Pathol. 2020, 102, 193-199. [CrossRef]

10. Gapasin, R.M.; Garcia, R.P.; Christine, T.; De Cruz, C.S.; Borines, L.M. Fruit Bronzing: A new disease affecting jackfruit caused by Pantoea stewartii (Smith) Mergaert et al. Ann. Trop. Res. 2014, 36, 17-31.

11. Hernández-Morales, A.; Pérez-Casillas, J.M.; Soria-Guerra, R.E.; VelázquezFernández, J.B.; Arvizu-Gómez, J.L. First report of Pantoea stewartii subsp. stewartii causing jackfruit bronzing disease in Mexico. J. Plant Pathol. 2017, $99,807$.

12. Newlands, N.K. Model-Based Forecasting of Agricultural Crop Disease Risk at the Regional Scale, Integrating Airborne Inoculum, Environmental, and Satellite-Based Monitoring Data. Front. Environ. Sci. 2018, 6, 63. [CrossRef]

13. Ayodele, V.O.; Olowe, O.M.; Afolabi, C.G.; Kehinde, I.A. Identification, assessment of diseases and agronomic parameters of Curcuma amada Roxb (Mango ginger). Curr. Plant Biol. 2018, 15, 51-57. [CrossRef]

14. Department of Agriculture (DOA). Phytosanitary Requirement for Exportation of Horticultural Produce from Malaysia 2021; Department of Agriculture: Putrajaya, Malaysia, 2021.

15. Xu, R.; Chen, Q.; Robleh Djama, Z.; Tambong, J.T. Miniprimer PCR assay targeting multiple genes: A new rapid and reliable tool for genotyping Pantoea stewartii subsp. stewartii. Lett. Appl. Microbiol. 2010, 50, 216-222. [CrossRef]

16. Gehring, I.; Wensing, A.; Gernold, M.; Wiedemann, W.; Coplin, D.L.; Geider, K. Molecular differentiation of Pantoea stewartii subsp. indologenes from subspecies stewartii and identification of new isolates from maize seeds. J. Appl. Microbiol. 2014, 116, 1553-1562. [CrossRef]

17. Correa, V.R.; Majerczak, D.R.; Ammar, E.-D.; Merighi, M.; Pratt, R.C.; Hogenhout, S.A.; Redinbaugh, M.G. The bacterium Pantoea stewartii uses two different type III secretion systems to colonize its plant host and insect vector. Appl. Environ. Microbiol. 2012, 78, 6327-6336. [CrossRef]

18. Rahma, H.; Sinaga, M.S.; Surahman, M. First report of Stewart's Wilt of maize caused by Pantoea stewartii subsp. stewartii in Bogor district, Indonesia. J. Int. Soc. Southeast Asian Agric. Sci. 2014, 20, 131-141.

19. Orio, A.G.A.; Brücher, E.; Plazas, M.C.; Sayago, P.; Guerra, F.; De Rossi, R.; Ducasse, D.A.; Guerra, G.D. First report of Stewart's wilt of maize in Argentina caused by Pantoea stewartii. Plant Dis. 2012, 96, 1819. [CrossRef]

20. Cui, D.; Huang, M.-T.; Hu, C.-Y.; Su, J.-B.; Lin, L.-H.; Javed, T.; Deng, Z.-H.; Gao, S.-J. First report of Pantoea stewartii subsp. stewartii causing bacterial leaf wilt of sugarcane in China. Plant Dis. 2021, 105, 1190. [CrossRef] [PubMed]

21. Jeger, M.; Bragard, C.; Candresse, T.; Chatzivassiliou, E.; Dehnen-Schmutz, K.; Gilioli, G.; Grégoire, J.; Jaques Miret, J.A.; MacLeod, A.; Navajas Navarro, M.; et al. Pest categorisation of Pantoea stewartii subsp. stewartii. EFSA J. 2018, 16, e05356. [PubMed]

22. Coplin, D.L.; Majerczak, D.R.; Zhang, Y.; Kim, W.-S.; Jock, S.; Geider, K. Identification of Pantoea stewartii subsp. stewartii by PCR and strain differentiation by PFGE. Plant Dis. 2002, 86, 304-311. [CrossRef]

23. EPPO. PM 7/60 (2) Pantoea stewartii subsp. stewartii. EPPO Bull. 2016, 46, 226-236. [CrossRef]

24. De Maayer, P.; Aliyu, H.; Vikram, S.; Blom, J.; Duffy, B.; Cowan, D.A.; Coutinho, T.A. Phylogenomic, pan-genomic, pathogenomic and evolutionary genomic insights into the agronomically relevant enterobacteria Pantoea ananatis and Pantoea stewartii. Front. Microbiol. 2017, 8, 1755-1756. [CrossRef] [PubMed] 
25. ITFN. Rust-Like Symptoms and Rot on Jackfruit: A Combination of Disease and Abiotic Factors? ITFN Tropical Fruit Network: Serdang, Malaysia, 2012; pp. 16-17.

26. Hernández-Morales, A.; Soria-Guerra, R.E.; Isiordia-Aquino, N.; Campos-Guillén, J.; Pacheco-Aguilar, J.R.; Martínez-Rizo, A.B.; Arvizu-Gómez, J.L. Association of Pantoea stewartii subsp. stewartii with ChrysSA genus flea beetles in jackfruit crops. J. Plant Pathol. 2021, 103, 539-547. [CrossRef]

27. Kini, K.; Agnimonhan, R.; Dossa, R.; Silué, D.; Koebnik, R. A diagnostic multiplex PCR scheme for identification of plantassociated bacteria of the genus Pantoea. bioRxiv 2018. [CrossRef]

28. dos Santos, R.F.; Spósito, M.B.; Ayres, M.R.; Sosnowski, M.R. Phylogeny, morphology and pathogenicity of Elsinoë ampelina, the causal agent of grapevine anthracnose in Brazil and Australia. J. Phytopathol. 2018, 166, 187-198. [CrossRef]

29. Kim, H.S.; Cheon, W.; Lee, Y.; Kwon, H.T.; Seo, S.T.; Balaraju, K.; Jeon, Y. Identification and characterization of Xanthomonas arboricola pv. juglandis causing bacterial blight of walnuts in Korea. Plant Pathol. J. 2021, 37, 137-151. [CrossRef] [PubMed]

30. Dumin, W.; Park, M.J.; Park, J.H.; Yang, C.Y.; Back, C.G. First report of black spot disease caused by Xanthomonas arboricola pv. pruni on plumcot in South Korea. Plant Dis. 2021, 105, 697. [CrossRef] [PubMed]

31. Filiz Doksöz, S.; Bozkurt, İ.A. A new and simple pathogenicity test using carrot slices for Pseudomonas savastanoi pv. savastanoi, causal disease agent of olive knot. J. Plant Pathol. 2020, 102, 1173-1177. [CrossRef]

32. Fredricks, D.N.; Relman, D.A. Sequence-based identification of microbial pathogens: A reconsideration of Koch's postulates. Clin. Microbiol. Rev. 1996, 9, 18-33. [CrossRef]

33. Riley, M.B.; Williamson, M.R.; Maloy, O. Plant disease diagnosis. Plant Health Instr. 2002. [CrossRef]

34. Lamichhane, J.R.; Venturi, V. Synergisms between microbial pathogens in plant disease complexes: A growing trend. Front. Plant Sci. 2015, 6, 385. [CrossRef]

35. Pariaud, B.; Ravigné, V.; Halkett, F.; Goyeau, H.; Carlier, J.; Lannou, C. Aggressiveness and its role in the adaptation of plant pathogens. Plant Pathol. 2009, 58, 409-424. [CrossRef]

36. Davidson, J.; Smetham, G.; Russ, M.H.; McMurray, L.; Rodda, M.; Krysinska-Kaczmarek, M.; Ford, R. Changes in aggressiveness of the Ascochyta lentis population in Southern Australia. Front. Plant Sci. 2016, 7, 393. [CrossRef]

37. Taylor, A.; Coventry, E.; Jones, J.E.; Clarkson, J.P. Resistance to a highly aggressive isolate of Sclerotinia sclerotiorum in a Brassica napus diversity set. Plant Pathol. 2015, 64, 932-940. [CrossRef]

38. Rodrigues, L.M.R.; Almeida, I.M.G.; Patrício, F.R.A.; Beriam, L.O.S.; Maciel, K.W.; Braghini, M.T.; Filho, O.G. Aggressiveness of strains and inoculation methods for resistance assessment to bacterial halo blight on coffee seedlings. J. Phytopathol. 2017, 165, 105-114. [CrossRef]

39. Fantinel, V.S.; Muniz, M.F.B.; Poletto, T.; Harakava, R.; Ciotta, M.N.; Savian, L.G.; Favaretto, R.F.; Krahn, J.R.T. Pathogenicity and susceptibility/resistance reaction of feijoa (Feijoa sellowiana) cultivars to anthracnose. Rev. Bras. Ciências Agrári 2020, 15, 1-7. [CrossRef]

40. Rahma, H.; Sinaga, M.S.; Surahman, M. Tingkat Keterjadian Penyakit Layu Stewart pada Benih dan Respon beberapa Varietas Jagung terhadap Infeksi Pantoea stewartii subsp. stewartii. Jurnal Hama dan Penyakit Tumbuhan Tropika 2013, 13, 1-9. [CrossRef]

41. Goszczynska, T.; Botha, W.J.; Venter, S.N.; Coutinho, T.A. Isolation and identification of the causal agent of brown stalk rot, a new disease of maize in South Africa. Plant Dis. 2007, 91, 711-718. [CrossRef] [PubMed]

42. RAL Deutsches Institut für Güte sicherung und Kennzeichnung. RAL K1 (RAL Classic Colour); RAL gemeinnützige GmbH: Sankt Augustin, Germany, 2019.

43. Schneider, C.A.; Rasband, W.S.; Eliceiri, K.W. NIH Image to ImageJ: 25 years of image analysis. Nat. Methods 2012, 9, 671-675. [CrossRef] [PubMed]

44. Freeman, N.D.; Pataky, J.K. Levels of Stewart's wilt resistance necessary to prevent reductions in yield of sweet corn hybrids. Plant Dis. 2001, 85, 278-1284. [CrossRef]

45. Campbell, L.; Madden, L.V. The Epidemiology of Plant Diseases; Wiley-Interscience: New York, NY, USA, 1990.

46. R Core Team. R: A Language and Environment for Statistical Computing; R Foundation for Statistical Computing: Vienna, Austria, 2021.

47. RStudio Team. RStudio: Integrated Development Environment for R; RStudio IDE: Boston, MA, USA, 2021.

48. Wickham, H.; Bryan, J. Readxl: Read Excel Files. In R Package Version 1.3.1. 2019. Available online: https://cran.r-project.org/ web/packages/readxl/index.html (accessed on 18 July 2021).

49. Henry, L.; Wickham, H. Purrr: Functional Programming Tools. In R Package Version 0.3.4. 2020. Available online: https: / / cran.r-project.org/web/packages/purrr/index.html (accessed on 18 July 2021).

50. Wickham, H.; Averick, M.; Bryan, J.; Chang, W.; McGowan, L.D.; François, R.; Grolemund, G.; Hayes, A.; Henry, L.; Hester, J.; et al. Welcome to the Tidyverse. J. Open Source Softw. 2019, 4, 1686. [CrossRef]

51. Neuwirth, E. RColorBrewer: ColorBrewer Palettes. In R Package Version 1.1-2. 2014. Available online: https://cran.r-project.org/ web / packages / RColorBrewer/index.html (accessed on 18 July 2021).

52. Ogle, D.; Doll, J.; Wheeler, P.; Dinno, A. FSA: Fisheries Stock Analysis. In R Package Version 0.9.0. 2021. Available online: https:/ / github.com/droglenc/FSA (accessed on 18 July 2021).

53. Mangiafico, S. Rcompanion: Functions to support Extension Education Program Evaluation. In R Package Version 2.4.1. 2020. Available online: http:/ / rcompanion.org/ (accessed on 18 July 2021). 
54. Pedersen, T.L. Patchwork: The Composer of Plots. In R Package Version 1.1.1. 2020. Available online: https://CRAN.R-project. org / package = patchwork (accessed on 18 July 2021).

55. Duong, D.A.; Jensen, R.V.; Stevens, A.M. Discovery of Pantoea stewartii ssp. stewartii genes important for survival in corn xylem through a Tn-Seq analysis. Mol. Plant Pathol. 2018, 19, 1929-1941. [CrossRef] [PubMed]

56. Asselin, J.E.; Lin, J.; Perez-Quintero, A.L.; Gentzel, I.; Majerczak, D.; Opiyo, S.O.; Zhao, W.; Paek, S.M.; Kim, M.G.; Coplin, D.L.; et al. Perturbation of maize phenylpropanoid metabolism by an AvrE family type III effector from Pantoea stewartii. Plant Physiol. 2015, 167, 1117-1135. [CrossRef]

57. Ham, J.H.; Majerczak, D.; Ewert, S.; Sreerekha, M.-V.; Mackey, D.; Coplin, D. WtsE, an AvrE-family type III effector protein of Pantoea stewartii subsp. stewartii, causes cell death in non-host plants. Mol. Plant Pathol. 2008, 9, 633-643. [CrossRef]

58. De Pinto, M.C.; Lavermicocca, P.; Evidente, A.; Corsaro, M.M.; Lazzaroni, S.; De Gara, L. Exopolysaccharides produced by plant pathogenic bacteria affect ascorbate metabolism in Nicotiana tabacum. Plant Cell Physiol. 2003, 44, 803-810. [CrossRef] [PubMed]

59. Roper, M.C. Pantoea stewartii subsp. stewartii: Lessons learned from a xylem-dwelling pathogen of sweet corn. Mol. Plant Pathol. 2011, 12, 628-637. [CrossRef] [PubMed]

60. Fatima, U.; Senthil-Kumar, M. Plant and pathogen nutrient acquisition strategies. Front. Plant Sci. 2015, 6, 750. [CrossRef]

61. KADA. Varieties Registered For National Crop List; Kemubu Agricultural Development Authority: Kota Bharu, Kelantan, Malaysia, 2018.

62. Grabowski, M. Angular Leaf Spot. Available online: https://extension.umn.edu/diseases/angular-leaf-spot (accessed on 22 June 2020).

63. Meng, X.; Chai, A.; Shi, Y.; Xie, X.; Ma, Z.; Li, B. Emergence of Bacterial Soft Rot in Cucumber Caused by Pectobacterium carotovorum subsp. brasiliense in China. Plant Dis. 2017, 101, 279-287. [CrossRef]

64. Frenkel, O.; Brewer, M.T.; Milgroom, M.G. Variation in pathogenicity and aggressiveness of Erysiphe necator from different Vitis spp. and geographic origins in the eastern United States. Phytopathology 2010, 100, 1185-1193. [CrossRef]

65. Bartoli, C.; Roux, F.; Lamichhane, J.R. Molecular mechanisms underlying the emergence of bacterial pathogens: An ecological perspective. Mol. Plant Pathol. 2015, 17, 303-310. [CrossRef] 